\title{
INTRODUCCION AL TEMA DE MICOTOXINAS Y MICOTOXICOSIS
}

Luis López Valladares

Facultad de Ciencias Químicas y

Farmacéuticas Universidad de Chile

Santiago

Palabras Clave: Micotoxinas, Micotoxicosis.

Key Words: Mycotixins, Mycotoxicoses.

\section{SUMARIO}

Se presenta un panorama general sobre las principales micotoxinas y sus efectos sobre la salud humana y animal.

\section{INTRODUCCION}

a presencia de hongos en la naturaleza se manifiesta de diferentes maneras, expresándose sus potencialidades biológicas en todos los campos. Muchos son capaces de colonizar los más variados sustratos, encontrando así especies de distribución universal. De esta forma influyen directamente $o$ a veces en forma indirecta en la vida del hombre y de los animales.

Hasta hace algún tiempo, la creencia de la inocuidad de los hongos era generalizada, un crecimiento fúngico moderado en un producto alimenticio era considerado como una pequeña molestia, causante de un daño en la apariencia y posiblemente algún grado de pérdida o alteración. Casos de contaminación más intensa ya impedían su uso en la alimentación humana, y era entonces destinado a la animal (López, 1985).

Las pérdidas totales de alimentos o de materias primas son generalmente difíciles de estimar, pero se ha calculado por ejemplo, que éstas ascienden' a cerca de un $45 \%$ de la producción anual en países desarrollados de regiones tropicales. El daño producido por hongos contribuye sustancial mente a esas pérdidas, lo cual es un gran impacto al aporte mundial para la alimentación (Riemann y Bryan, 1979). Datos provenientes de EE.UU. señalan pérdidas de granos que ascendieron a más de 400 millones de dólares, luego de epidemias causadas por aflatoxinas en 1977 y 1980 (Christopher y Fulcher, 1984).

\section{SUMMARY}

\section{[Introduction to mycotoxins and mycotoxicoses]}

A general panorama over the main mycotoxins and their effects in human and animal health is presented.

Por otra parte, el hallazgo de sustancia tóxicas producidas por hongos en determinadas condiciones, y su eventual acción sobre la salud tanto del hombre como de los animales, han despertado un interés que ha ido en aumento en los últimos años y que se ha visto reflejado en la recopilación de un gran número de antecedentes destinados a la solución del problema que ésto significa.

\section{MICOTOXINAS}

Las micotoxinas son productos metabólicos elaborados por hongos, que en bajas concentraciones pueden ocasionar cuadros clínicos de gravedad en animales. No está complemente claro todavía, si se trata de metabolitos primarios o secundarios, o si son excretados al medio ambiente o permanecen dentro de la célula.

Se conocen alrededor de 200 tipos de hongos que pueden elaborar toxinas al crecer en determinados sustratos y bajo condiciones especiales. $\mathrm{La}$ mayoría de ellos pertenecen a formas imperfectas (Deuteromycetes), los cuales se caracterizan por su heterocariosis, es decir por ser genéticamente muy inestables.

El efecto que producen las micotoxinas en el organismo es variado. En la Tabla I se presentan algunos de estos efectos, la tóxina que lo produce y el hongo responsable de la elaboración del tóxico. 
Tabla I

Espectro de acción farmacológica de algunas micotoxinas

\begin{tabular}{|c|c|c|}
\hline Tipo de efecto & Toxina & Hongo \\
\hline Cardiotóxico & $\begin{array}{l}\text { Toxina Phomopsis } \\
\text { Toxina Viridicatum }\end{array}$ & $\begin{array}{l}\text { Phomopsis leptostromiformis } \\
\text { Penicillium viridicatum }\end{array}$ \\
\hline Dermatotóxico & Toxina T-2 y deriv. & Fusarium spp., Trichoderma spp. \\
\hline Emético & Toxina $\mathrm{T}-2$ & Fusarium spp., Trichoderma spp. \\
\hline Aucinćrane & Vomitoxina (Desoxinivalenol) & Fusarium spp., Trichoderma spp. \\
\hline Alucinógeno & $\begin{array}{l}\text { Ergotoxina (L̀SD) } \\
\text { Etanol }\end{array}$ & $\begin{array}{l}\text { Claviceps purpurea y otros } \\
\text { Saccharomyces cerevisiae y otros }\end{array}$ \\
\hline Hemolítico & $\begin{array}{l}\text { Hemotoxina } \\
\text { Hemotoxina }\end{array}$ & $\begin{array}{l}\text { Aspergillus fumigatus } \\
\text { Phoma sorghina }\end{array}$ \\
\hline $\begin{array}{l}\text { Hepatotóxico y } \\
\text { hepatocarcinógeno }\end{array}$ & Aflatoxina & $\begin{array}{l}\text { Aspergillus flavus, } \\
\text { Aspergillus parasiticus, }\end{array}$ \\
\hline & Sterigmatocistina & Aspergillus versicolor y otros \\
\hline Nefrotóxico & $\begin{array}{l}\text { Ochratoxina A } \\
\text { Citrina }\end{array}$ & $\begin{array}{l}\text { Aspergillus ochraceus y otros } \\
\text { Penicillium spp., Aspergillus spp. }\end{array}$ \\
\hline Neurotóxico & $\begin{array}{l}\text { Citreoviridina } \\
\text { Roquefortina }\end{array}$ & $\begin{array}{l}\text { Penicillium spp. } \\
\text { Penicillium roqueforti }\end{array}$ \\
\hline Estrogénico & Zearalenona & Fusarium spp. \\
\hline Fotosensibilizador & $\begin{array}{l}\text { Sporidesmina } \\
\text { 8-Metoxipsoraleno }\end{array}$ & $\begin{array}{l}\text { Pithomyces chartarum } \\
\text { Sclerotinia sclerotiorum }\end{array}$ \\
\hline Teratogénico & $\begin{array}{l}\text { Ochratoxina } \mathrm{A} \\
\text { Aflatoxina } \mathrm{B}_{1}\end{array}$ & $\begin{array}{l}\text { Aspergillus ochraceus y otros } \\
\text { Aspergillus flavus, Aspergillus } \\
\text { parasiticus }\end{array}$ \\
\hline & Rubratoxina B & $\begin{array}{l}\text { Penicillium rubrum, Penicillium } \\
\text { purpurogenum }\end{array}$ \\
\hline Tremorgénico & Penitrem A & $\begin{array}{l}\text { Penicillium crustosum, Penicillium } \\
\text { granulatum }\end{array}$ \\
\hline & $\begin{array}{l}\text { Fumitremorgeno } \\
\text { Paxilina }\end{array}$ & $\begin{array}{l}\text { Aspergillus fumigatus } \\
\text { Penicillium paxilli }\end{array}$ \\
\hline Ulcerogénico & Austdiol & Aspergillus ustus \\
\hline $\begin{array}{l}\text { Producción de células } \\
\text { multinucleadas }\end{array}$ & Citochalasina & Phoma spp., Helmintosporium spp. \\
\hline
\end{tabular}

\section{FACTORES QUE CONDICIONAN LA PRODUCCION DEL TOXICO}

De acuerdo a su composición química, los productos alimenticios constituyen un buen sustrato para el crecimiento y multiplicación de los hongos. Además de los nutrientes, es necesario considerar la influencia de otros factores en el desarrollo del hongo y la eventual producción del tóxico (Frank, 1980a). Entre ellos se pueden citar:

a. Temperatura: en general, la temperatura óptima de crecimiento del hongo es diferente a la de producción del tóxico. En la mayoria de los casos existen variaciones de acuerdo a la cepa fúngica y el sustrato en el cual se encuentre. A temperaturas cercanas a $8^{\circ} \mathrm{C}$, ya no se observa producción de aflatoxina, pero es necesario establecer un control adecuado sobre todo en alimentos refrigerados, ya que se ha observado que al ser puestos a temperaturas superiores se puede obtener en pocas horas una concentración considerable del tóxico. Existen sin embargo, cepas que pueden elaborar toxinas a temperaturas cercanas a 0 으 C en concentraciones mayores a las obtenidas a $250 \mathrm{C}$, como es el caso de la producción de patulina por Penicillium expansum y Byssochlamys nivea.

b. Tiempo: la producción de toxina en el tiempo depende en gran medida de la cepa fúngica, sus- 
trato y temperatura. En condiciones óptimas, se ha demostrado que la concentración máxima de aflatoxina se alcanza luego de 8 a 14 días. Esta permanece relativamente constante en el micelio, debido a degradación y remetabolización, mientras que en el sustrato inmediato es posible observar una franca reducción.

En la producción de patulina se ha observado en la mayoría de los casos, un aumento de la concentración alcanzando un máximo a los 10-15 días y una posterior reducción debida frecuentemente a la alcalinización del medio o a la presencia de grupos - $\mathrm{SH}$ en el sustrato.

c. $\mathrm{pH}$ : el valor de $\mathrm{pH}$ generalmente ejerce poca influencia en la producción de toxinas y en el crecimiento del hongo. Para aflatoxinas por ejemplo, pH entre 5 y 7 parecerían ser óptimos para su producción, aunque también es posible obtenerla entre $\mathrm{pH} 1.8$ y 8.0. Al utilizar cepas de Aspergillus versicolor, el $\mathrm{pH}$ para la producción de sterigmatocistina (pH 8) era diferente al óptimo para el crecimiento (pH 5). Mayor especificidad se ha encontrado en el caso de patulina, la cual requiere de $\mathrm{pH}$ entre 3 y 6.5 por su inestabilidad en medios neutros y alcalinos. Sin embargo, algunos autores han reportado estudios en donde se señala la posibilidad de encontrarla hasta en valores de $\mathrm{pH} 8.6$, sobre todo en sustratos deshidratados tales como pan y productos horneados.

d. Luz: se ha demostrado que en algunas especies de Penicillium y Fusarium la esporulación es influenciada por la presencia de luz. Debido a que esta influencia es sólo frente a determinadas cepas, es difícil generalizar su efecto en el metabolismo fúngico. Esto es válido tanto para el crecimiento como para la producción del tóxico.

e. Humedad: la actividad de agua de un determinado sustrato puede inhibir el desarrollo fúngico, pero no tendría efecto sobre la producción del tóxico, ya que una vez que comienza la formación de micelio, la toxinogénesis se realizaría en forma paralela. Esta hipótesis sin embargo, no concuerda con resultados obtenidos al investigar la producción de patulina, donde se ha demostrado que los requerimientos en términos de $a_{w}$ para la toxinogénesis son más exigentes que loŝ necesarios para permitir el desarrollo del hongo.

f. Atmósfera: diferentes autores reportan, para el caso específico de aflatoxinas, que una disminución del oxígeno al $1 \%$ en la atmósfera, afecta negativamente la producción del tóxico, aunque al aumentar el contenido de $\mathrm{CO}_{2}$ hasta un $80 \%$ no se observa una inhibición del desarrollo del hongo. Solamente a concentraciones de $0,1 \%$ de oxígeno inhiben el desarrollo del hongo. Con respecto a sterigmatocistina, el aumento del contenido de $\mathrm{CO}_{2}$ hasta un $90 \%$ en una atmósfera con un $10 \%$ de aire, como así también en concentraciones de $10 \%$ de $\mathrm{CO}_{2}$ en una atmósfera de nitrógeno, inhiben tanto el desarrollo como la producción del tóxico. La producción de patulina se ve inhibida en atmósfera de nitrógeno con bajo contenido de oxígeno (menos de $1 \mathrm{ppm}$.) aunque se han reportado algunas cepas que pueden crecer, pero en formas bastante débil. De especial interés es el caso de Byssochlamys nivea el cual puede causar problemas aún en atmósferas con presión parcial de oxígeno de hasta $0,0001 \%$.

g. Factores de tipo químico: entre este tipo de factores, que favorecen la producción de aflatoxina se pueden citar: glucosa $(5-15 \%)$, fructosa $(6,6-$ $15 \%)$, sacarosa $(2,5-8,5 \%)$, extracto de levadura $(3,87 \%)$, peptona $(0,3-1,0 \%), \mathrm{Zn}^{+2}(5-250 \mathrm{mg} / \mathrm{l})$, $\mathrm{Ca}^{+2}(100 \mathrm{mg} / \mathrm{l}), \mathrm{Fe}^{+2}(250 \mathrm{mg} / \mathrm{l}), \mathrm{Mg}^{+2}(50$ $\mathrm{mg} / \mathrm{l})$, entre otros. El efecto inhibidor puede ser logrado con lactosa $(6,6 \%), \mathrm{Ag}^{+}(0,2 \mathrm{mg} / \mathrm{l}) . \mathrm{Ba}^{+2}$ $(4 \mathrm{mg} / \mathrm{l}), \mathrm{Hg}^{+2}(5 \mathrm{mg} /)$, como así también con algunos productos. fungicidas, insecticidas $y$ preservantes antifúngicos.

Los productos intermediarios del ciclo del ácido cítrico (succinato, malato, fumarato, alfa cetoglutamato y citrato) estimulan la producción de sterigmatocistina. Una inhibición de ésta se puede lograr con la adición de ácido láctico, cítrico y sórbico al sustrato.

La producción de patulina puede estimularse por lactosa e inhibirse por caseina. Al adicionar ácido cítrico $(0,75 \%)$ y ácido láctico $(0,75 \%)$ se ha visto que influye en el crecimiento del hongo pero no en la producción de la toxina.

h. Estado ñsico del sustrato: en el caso específico de contaminación fúngica en granos, ésta es tanto mayor (la producción de aflatoxinas), mientras mayor sea la superficie expuesta. Lo mismo puede ser aplicado a otros tipos de sustratos alimenticios, como por ejemplo frutas, vegetales, sopas y otros productos deshidratados, donde la superficie expuesta a la contaminación es considerable.

i. Capacidad toxigénica del hongo: no todas las cepas de hongos toxigénicos son capaces de producir igual cantidad de toxinas. Algunos autores afirman que cerca del $50 \%$ de los hongos aislados de alimentos y forrajes son capaces de producir aflatoxinas que causaron la muerte de diversos animales de experimentación. Generalmente las cepas de climas cálidos son mejores productoras de aflatoxina que las de climas templados y fríos.

j. Presencia de otros hongos: la competencia 
entre los diferentes tipos de hongos presentes en un sustrato, puede afectar la producción de un determinado producto tóxico. Un crecimiento masivo de cepas tales como Penicililium caseicolum, $\mathbf{P}$. roqueforti y $\mathbf{P}$. nalgiovense puede inhibir la producción de aflatoxinas. Otros pueden inclu. so llegar a desdoblar la toxina ya formada, como es el caso de Scopulariopsis brevicaulis y Rhizopus oryzae.

\section{PRINCIPALES MICOTOXINAS}

\section{AFLATOXINAS}

Constituyen un grupo de metabolitos secundarios producidos por hongos, de potente acción tóxica y carcinógena frente a animales y que han sido consideradas epidemiológicamente como carcinógenos ambientales para el hombre (Müller y Loeffler, 1982).

Son las más importantes y ampliamente estudiadas. El principal hongo productor, a quien debe su nombre, es Aspergillus flavus, pero también se ha comprobado la existencia de otras especies toxinogénicas como por ejemplo A. parasiticus, A. niger, A. wentii, A. ruber, Penicillium citrinum, $\mathbf{P}$. glabrum, $\mathbb{P}$. puberulum y $\mathbb{P}$. variable, entre otros.

\section{Estructura đuímica}

Pertenecen al grupo de derivados de bisfuranoisocumarina. Son 4 los compuestos que se producen principalmente, aflatoxina $\mathrm{B}_{1}$ y $\mathrm{B}_{2}$ designadas de esa manera por presentar una intensa fluorescencia azul bajo la luz UV; y las aflatoxinas $G_{1} y$ $\mathrm{G}_{2}$ de fluorescencia amarillo-verdosa.

${ }^{2}$ Estos 4 compuestos poseen estrutura química similar, posteriormente se encontraron 2 productos del metabolismo de $\mathrm{B}_{1}$ y $\mathrm{B}_{2}$ en leche de vacas alimentadas con forrajes contaminados, las que fueron denominadas $\mathrm{M}_{1}$ y $\mathrm{M}$, que correspondían a derivados hidroxilados de las antes mencionadas.

En 1966 se descubrieron la $B_{2 a}$ y $G_{2 a}$, derivados hidroxilados de $\mathrm{B}_{1}$ y $\mathrm{G}_{1}$, que presentañ escasa toxicidad. Posteriormente se han encontrado una serie de otros derivados, como por ejemplo $\mathrm{GM}_{1}$, $\mathrm{R}^{2}, \mathrm{P}_{1}, \mathrm{H}_{1}, \mathrm{Q}_{1}, \mathrm{~B}_{3}, 1-\mathrm{OCH}_{3} \mathrm{~B}_{2}, 1-\mathrm{CH}_{3} \mathrm{G}_{2}$, $1-$

En la Figura 1 se presenta la estructura química de la aflatoxina $B_{1} y$ de sus principales productos derivados.

\section{Figura 1}

\section{Aflatoxina $B_{1}$ y algunos derivados}

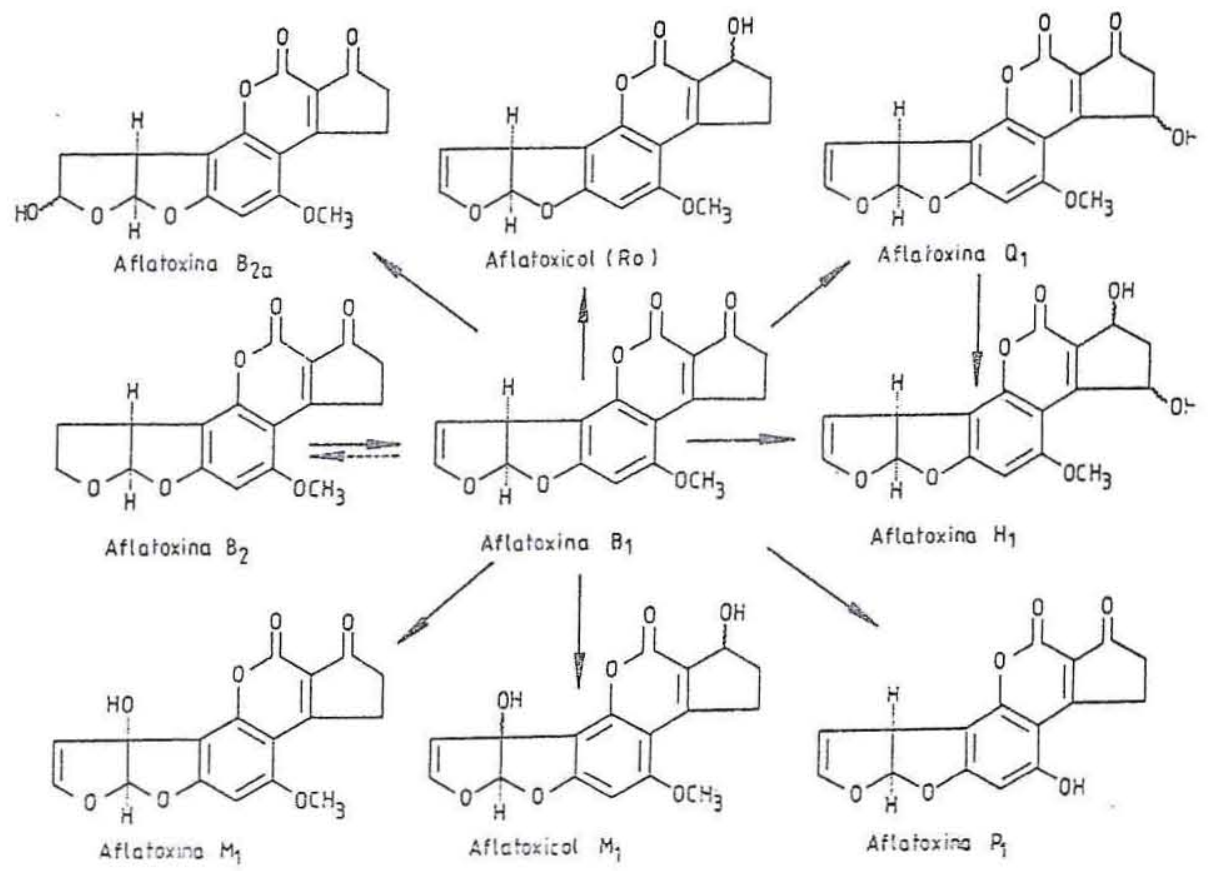




\section{Características químicas}

Las aflatoxinas son solubles en metanol, cloroformo y otros solventes polares, pero escasamente solubles en agua $(10-30 \mathrm{ug} / \mathrm{ml})$.

Absorven intensamente la luz UV (362-363 $\mathrm{nm}$ ) con coeficiente de extinsión que varían de 14700 para $B_{2}$ a 21800 para $B_{1}$. La emisión de fluorescencia se produce a $425 \mathrm{~nm}$ para $\mathrm{B}_{1}$ y $\mathrm{B}_{2}$. Son relativamente inestables, al estado de sustancia pura, a la luz y al aire.

La presencia de un anillo lactónico en su molécula, la hace susceptible a la hidrólisis alcalina; sin embargo, si el tratamiento alcalino es suave, una acidificación puede revertir la reacción.

Por el proceso ordinario de cocción no se logra su destrucción, pero pueden ser afectadas al ser tratadas con amoniaco o con soluciones de hipoclorito de sodio. No provocan reacción inmunológica, lo que también es aplicable a otras micotoxinas.

\section{Actividad biológica.}

Toxicidad: las aflatoxinas B1 en particular, poseen una toxicidad aguda frente a una gran variedad de organismos vivos en los que se incluyen animales domésticos y de laboratorio, cultivo de células, microorganismos y plantas. La patología de la toxicidad en animales está relacionada principalmente con el hígado.

En la Tabla II se presentan algunas LD50 de diferentes aflatoxinas.

Tabla-II

Toxicidad aguda de aflatoxinas en patos de 1 día.

\begin{tabular}{cc}
\hline Afiatoxina & $\begin{array}{r}\text { LD } 50 \text { (7 días) } \\
\text { en ug/50g }\end{array}$ \\
\hline $\mathrm{B}_{1}$ & 18,2 \\
$\mathrm{~B}_{2}$ & 84,8 \\
$\mathrm{G}_{1}$ & 39,2 \\
$\mathrm{G}_{2}$ & 172,5 \\
\hline
\end{tabular}

Carcinogenia: se ha demostrado la actividad carcinogénica en varias especies animales incluyendo roedores, primates, aves y peces. El hígado era el órgano principalmente afectado, en el que se induce carcionomas hepatocelulares y otros tipos de tumores. Sin embargo, bajo algunas circunstancias se ha visto incidencia de tumores en otros órga- nos. Estos dependen del tipo de aflatoxina inoculada, especie animal y dosis del tóxico (Riemann y Bryan, 1979).

Mutagenicidad: la potencia mutagénica de aflatoxina $\mathrm{B}_{1}$ se ha demostrado al efectuar observaciones de dâno cromosomal mediante tinciones y técnicas microscópicas apropiadas y de expresiones genéticas alteradas en una gran variedad de sistemas procarióticos y eucarióticos.

Teratogenicidad: existen escasas publicaciones relacionadas con la teratogenicidad de aflatoxina B1 en mamíferos. Ensayos efectuados con hamsters demostraron su susceptibilidad, la cual se manifestó en severas malformaciones fetales tales como encefalías, desorganización en los túbulos renales y en un pronunciado retardo en el crecimiento. Las dosis de $4 \mathrm{mg} / \mathrm{kg}$ fueron aplicadas intraperitonealmente en el octavo día de preñez.

\section{Biosíntesis y mecanismo de acción.}

Hasta el momento parece ser que las aflatoxinas provienen de una derivación de la biosíntesis de los ácidos grasos, a partir de acetato y malonato en la fase estacionaria del crecimento.

Se ha observado que la aflatoxina B1 causa graves alteraciones en la síntesis de ácidos nucleicos y proteínas en el hígado al ser administrada a ratas en dosis agudas. La inhibición de la síntesis de DNA, RNA nuclear y la alteración de la transcripción de genes aparece rápidamente luego que el tóxico es administrado (Wogan, 1969).

\section{STERIGMATOCISTINA}

Las sterigmatocistinas constituyen un grupo de metabolitos fúngicos estructuralmente relacionados con las aflatoxinas.

Son elaboradas principalmente por Aspergillus versicolor, A. nidulans y otros, especialmente en sustratos como por ejemplo granos de cereales, quesos y alimentos para animales.

\section{Estructura química.}

Se caracteriza por un núcleo xantónico unido a un dihidrodifurano o a un tetrahidrodifurano. Además de la toxina principal, sterigmatocistina, se han identificado algunos derivados, producto de cultivos experimentales de cepas fúngicas. Entre ellas se incluyen aspertoxina (Aspergillus flavus), $\mathrm{O}$-metilsterigmatocistina (A flavus), 5-metoxisterigmatocistina (A. versicolor), 6-dimetilsterigmatocistina (A. versicolor), dihidro-O-metilsterigma- 
tocistina (A. flavus), dihidrosterigmatocistina (A. versicolor) y dihidrodemetilsterigmatocistina (A. versicolor). Estos derivados no han sido detectados en productos alimenticios y es poco lo que se conoce acerca de sus propiedades toxicológicas.

En la Figura 2 se presenta la estructura química de sterigmatocistina y de sus principales derivados.

Figura 2

Sterigmatocistina y derivados<smiles>[R20]Oc1cc2c(c3oc4c([R20])ccc([R6])c4c(=O)c13)C1([R])C=COC1O2</smiles>

(a)

(a)

Sterigma toc is tina

Aspertoxina

0 -metilsterigmatocistina

5 -metoxis terigmatocistina

6 - demetilsterigmatocis tina

(b)

Dihidr os terigmatocis tina

Dihidro-0-metilsterigmatocistina

Dihidrodemetilsterigmatocistina

\section{Características químicas}

Son muy poco solubles en agua y en general sus propiedades químicas son similares a las presentadas por las aflatoxinas.

\section{Actividad biológica.}

Poseen varias similitudes con las aflatoxinas en cuanto a su actividad biológica. La toxicidad aguda oral para ratas machos se produce con dosis de $166 \mathrm{mg} / \mathrm{kg}$ y para hembras con $120 \mathrm{mg} / \mathrm{kg}$. Exámenes histológicos demuestran necrosis en túbu. los renales, hígado y algunos daños al miocardio. Intraperitonealmente se ha visto que la LD50 es de $60 \mathrm{mg} / \mathrm{kg}$ y produce, además de los daños ya<smiles>[R17]c1cccc2oc3c4c(cc([R20])c3c(=O)c12)OC1OCCC41</smiles>

(b)

\begin{tabular}{llll}
$R$ & $\mathrm{R}_{1}$ & $\mathrm{R}_{2}$ & $\mathrm{R}_{3}$ \\
\hline $\mathrm{H}$ & $\mathrm{CH}_{3}$ & $\mathrm{H}$ & $\mathrm{H}$ \\
$\mathrm{OH}$ & $\mathrm{CH}_{3}$ & $\mathrm{CH}_{3}$ & $\mathrm{H}$ \\
$\mathrm{H}$ & $\mathrm{CH}_{3}$ & $\mathrm{CH}_{3}$ & $\mathrm{H}$ \\
$\mathrm{H}$ & $\mathrm{CH}_{3}$ & $\mathrm{H}$ & $\mathrm{OCH}_{3}$ \\
$\mathrm{H}$ & $\mathrm{H}$ & $\mathrm{H}$ & $\mathrm{H}$
\end{tabular}

\begin{tabular}{ll}
$R$ & $\mathrm{R}_{1}$ \\
\hline $\mathrm{CH}_{3}$ & $\mathrm{H}$ \\
$\mathrm{CH}_{3}$ & $\mathrm{CH}_{3}$ \\
$\mathrm{H}$ & $\mathrm{H}$
\end{tabular}

señalados, una peritonitis pronunciada. Dosis subcutáneas de $500 \mathrm{ug} / \mathrm{rata}$, aplicadas en dosis sucesivas se manifiestan en sarcomas y tumores hepáticos.

Biosíntesis y mecanismo de acción.

Dado que tanto las sterigmatocistinas como las aflatoxinas contienen en su estructura química el sistema de anillos furobenzofurano, se ha postulado que ellas tienen una vía biogenética común. Incluso se ha propuesto que las aflatoxinas podrían ser derivados de la sterigmatocistina. Singh y Hsieh (1976) han sostenido que la sterigmatocistina es convertida en aflatoxina $B_{1}$ por acción de Aspergillus parasiticus, de acuerdo a la siguiente 
secuencia metabólica: acetato - averufina - acetato versiconal - versicolorina A - sterigmatocistina aflatoxina $B_{1}$.

Con respecto al mecanismo de acción, se ha demostrado la acción inhibidora frente a la síntesis de DNA.

\section{PATULINA}

Fue aislada en 1943 de un filtrado proveniente de un cultivo de Penicillium patulum y $\mathbf{P}$. expansum, observando su activo poder antibiótico frente a cepas gram positivo y negativo, como también sobre dermatofitos y Candida albicans. Más tarde se comprobó que la dosis terapéutica era muy cercana a la dosis tóxica, por lo cual se desistió de su uso (Frank, 1980b).

En la literatura se la encuentra con varios sinónimos, como por ejemplo claviformina, clavatina, claracina, expansina, gigantina, leucopina, micoina $C$, penatina, penicidina y tercinina.

Puede ser producida además por hongos tales como Penicillium claviforme, P. cyclopium, P. granulatum, P. lapidosum, P. melinii, P. oxalicum, P. terrestre, P. viridicatum, Aspergillus clavatus, A. giganteus, A. terreus, Byssochlamys nivea y $\mathrm{B}$. fulva.

\section{Estructura química.}

Su estructura corresponde a una lactona (4. hidroxifuropirano) alfa, beta no saturada, perteneciente al grupo de las gamma pironas.

La fórmula se presenta en la Figura 3.

\section{Figura 3}

\section{Patulina}

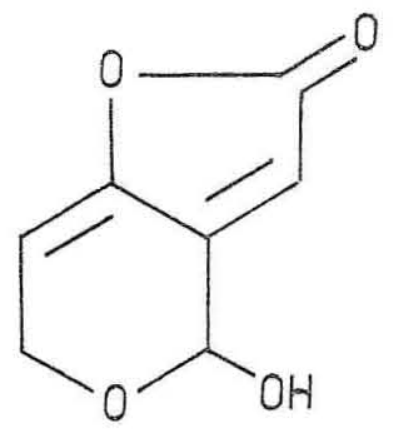

\section{Características g̣uímicas.}

Es soluble en agua, etanol, cloroformo y varios otros solventes orgánicos pero presenta baja solubilidad en benzol, hexano, éter de petróleo y grasas.

El espectro al UV presenta un máximo a 276 nm. Es prácticamente estable en medios ácidos (hasta $\mathrm{pH} 6,5$ ), pero a valores superiores se rompe el anillo lactónico perdiendo de esa forma su actividad biológica.

En medio ácido es estable hasta una temperatura de $1250 \mathrm{C}$, lo cual presenta importancia en lo que se refiere a los procesos utilizados en la elaboración de productos alimenticios. Puede ser producida en cantidades apreciables a temperaturas de incluso $-10 \mathrm{C}$ en algunos productos frutícolas, por lo cual se puede deducir que el almacenamiento de alimentos a temperaturas de refrigeración no causa un efecto protector en la elaboración de la toxina.

\section{Actividad biológica.}

La toxicidad aguda de patulina es relativamente elevada. Las LD50 para ratas fluctúan entre 25 y $35 \mathrm{mg} / \mathrm{kg}$, mientras que para pollos 170 $\mathrm{mg} / \mathrm{kg}$. Esto implica una gran diferencia de acuerdo al tipo de organismo afectado, lo que posiblemente puede ser explicado además por la acción protectora de grupos -SH presentes. Entre las lesiones ocasionadas en mamíferos se pueden mencionar hemorragias en el tracto gastrointestinal y daños hepáticos y renales. Se ha observado en experiencias realizadas in vitro, una ruptura de cromosomas y poliploidia en leucocitos humanos.

Más importante que la toxicidad aguda, poco probable de presentarse debido al contenido en concentraciones de ppb en los alimentos, es la posibilidad de producir toxicidad crónica, carcinogenia, teratogenia y mutagenicidad. Al respecto varios autores han reportado carcinogenia en ratas al aplicar dosis subcutáneas sucesivas.

\section{Biosíntesis y mecanismo de acción.}

La biosíntesis se produce a partir de glucosa, vía acetil $\mathrm{CoA}$, llegando finalmente a una ciclación por medio de una transformación oxidativa.

El efecto tóxico de patulina se ha atribuído a una inhibición del proceso de transcripción.

\section{ZEARALENONA}

Conocida también como toxina F-2, es un compuesto producido por miembros del género Fusa- 
rium; en particular F. graminearum. En menor proporción se ha visto la capacidad toxigénica de F. tricinctum y $\mathbf{E}$. moniliforme.

Se la ha identificado principalmente como contaminante de maíz, como también de trigo, avena, sorgo y sésamo. Las especies de Fusarium invaden los granos en desarrollo en períodos de lluvia intensa y proliferan en ellos debido a su alto contenido de humedad, ya sea por causa del clima húmedo durante la cosecha o por ser almacenados sin una etapa de secado previa. La frecuencia y concentración del tóxico varía de estación en estación. Los casos más nefastos reportados, señalan una contaminación que afectó al $17 \%$ de las muestras de granos recolectadas en el merca. do, presentando niveles promedios de $5 \mathrm{mg} / \mathrm{kg}$ ( 5 ppm).

\section{Estructura química}

Corresponde a una lactona macrocíclica, de la cual se conocen derivados tales como zearalenol, 6',8'-dihidroxizearaleno, 8'-hidroxizearalenona, 7'dehidrozearalenona y 5 -formilzearalenona.

Las estructuras químicas de los diferentes compuestos se presentan en la Figura 4.

\section{Figura 4}

\section{Zearalenona y derivados}

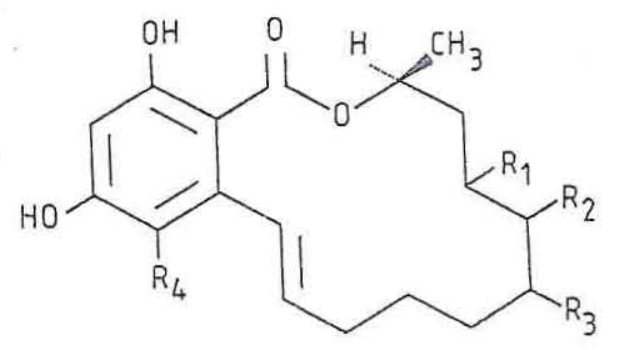

$\begin{array}{lllll}\text { Zearalenona } & \mathrm{H}_{2} & \mathrm{H}_{2} & =\mathrm{O} & \mathrm{H} \\ \text { Zearalenol } & \mathrm{H}_{2} & \mathrm{H}_{2} & \mathrm{OH} & \mathrm{H} \\ \text { 6', 8'-dihidroxizearaleno } & \mathrm{OH}_{2} & \mathrm{H}_{2} & \mathrm{OH} & \mathrm{H} \\ \text { 8'-hidroxizearalenona } & \mathrm{OH} & \mathrm{H}_{2} & =\mathrm{O} & \mathrm{H} \\ \text { 7'-dehidrozearalenona } & \mathrm{H} & \mathrm{H}^{\prime}=0 & \mathrm{H} \\ \text { 5-formilzearalenona } & \mathrm{H}_{2} & \mathrm{H}_{2}=0 & \mathrm{CHO}\end{array}$

\section{Características químicas}

Zearalenona es un compuesto blanco cristalino, de peso molecular 318, insoluble en agua, disulfito de carbono y tetracloruro de carbono. Presenta solubilidad en álcalis, éter, cloroformo, cloruro de metileno, acetonitrilo y alcoholes.

\section{Actividad biológica.}

El cerdo parece ser el organismo más sensible al tóxico; dosis de $1.5 \mathrm{mg} / \mathrm{kg}$ de forraje son suficientes para producir cuadros de vulvovaginitis. En ratas se ha visto que la LD50 oral es de 20 $\mathrm{g} / \mathrm{kg}$. Dosis orales de $10 \mathrm{mg}$ administradas diariamente durante 5 días, en ratas producen metaplasias vaginales.

La toxina y sus derivados son considerados estrógenos verdaderos, debido a que promueven una cornificación vaginal, sobre todo en ratas adultas.

\section{Biosíntesis y mecanismo de acción.}

Los estudios cinéticos y de degradación realizados con estos compuestos, han demostrado que son derivados de una vía acetato.

Como se mencionó anteriormente, el mecanismo de acción es similar al de los estrógenos.

\section{TRICOTECENOS}

Son metabolitos secundarios elaborados por cepas de Fusarium, Trichoderma, Myrothecium, Trichotecium, Acremonium, Stachybotrys, Cylindrocarpon y Verticimonosporium, cuya presencia ha sido confirmada en granos y forrajes (Siegtried, 1977). Se conocen en la actualidad cerca de $\$ 0$ compuestos entre los cuales se pueden citar deoxynivalenol (vomitoxina), toxina $T-2$, diacetoryscirpenol, neosolaniol, T-2 tetraol y otros.

Su producción es favorecida por humedad elevada y temperaturas entre 5 y $20^{\circ} \mathrm{C}$.

\section{Estructura química}

Son un grupo complejo de sesquiterpenoides que contienen un núcleo tricotecano, caracterizado por un enlace olefínico entre las posiciones $9 \mathrm{y}$ 10 y un grupo epoxi entre carbonos 12 y 13. Las estructuras químicas de los compuestos principales se presentan en la Figura 5 
Figura 5

\section{Tricotecenos}

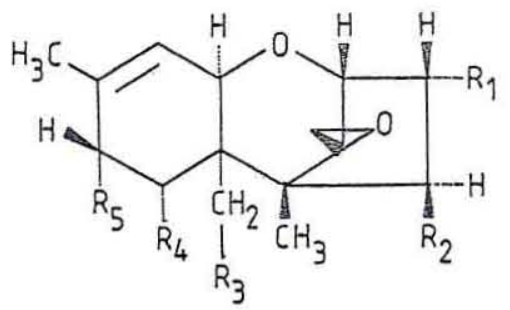

$\begin{array}{lllr}\text { Diacetaxyscirpenol } & \text { OH OAc OAc H } & \text { H } \\ \text { T-2 Tetraol } & \text { OH OH OH H } & \text { OH } \\ \text { Neosolaniol } & \text { OH OAc OAC H } & \text { OH } \\ \text { Vomitoxina } & \text { OH H OH OH } & =0 \\ \text { Toxina HT-2 } & \text { OH OH OAC H } & \text { O-isoVal } \\ \text { Toxina T-2 } & \text { OH OAc OAc H } & \text { O-isoVal }\end{array}$

$\begin{array}{llll}R_{1} & R_{2} & R_{3} & R_{4} \\ O H & O A c & O A c & H \\ O H & O H & O H & H \\ O H & O A c & O A c & H \\ O H & H & O H & O H \\ O H & O H & O A c & H \\ O H & O A c & O A c & H\end{array}$

$\mathrm{R}_{5}$

\section{Biosintesis y mecanismo de acción,}

No existe información referente a su biosíntesis, pero su mecanismo de acción ha sido bastante estudiado, sobre todo a nivel molecular. En gene$\mathrm{ral}$, la acción preponderante consiste en la inhibición de la síntesis proteica, pero todavía no se ha logrado construir un modelo inequívoco del real mecanismo de acción de esta toxina.

\section{OTRAS MICOTOXINAS}

\section{OCHRATOXINAS}

Son producidas por cepas de Aspergillus ochraceus, Penicillium cyclopium, $P$. viridicatum y otros.

Constituyen un grupo de 7 amidas isocumarínicas de la L-beta-fenilalanina. De estas la ochratoxina A es la que presenta mayor toxicidad. Su fórmula se presenta en la Figura 6.

\section{Figura 6}

\section{Ochratoxina A}

\section{Actividad biológica.}

Se ha demostrado su poder citotóxico para células humanas, en especial la toxina T-2 y diacetoxyscirpenol. Este último junto a fusarenona $\mathrm{X}$ y nivalenol son potentes agentes necrotizantes de la piel, lo que se ha observado al administrar dosis de sólo 0,2 ug de toxina en piel de cobayos.

En animales en general, la toxicidad de tricotecenos se caracteriza primeramente por sus efectos en la mucosa del estómago e intestino delgado, lo cual se traduce en una erosión y gastroenteritis hemorrágica severa. Vómitos y emesis es a menudo una característica observada luego de aplicar estos compuestos. En patos se ha inducido vómitos por aplicación de dosis de $0,1 \mathrm{mg} / \mathrm{kg}$ de toxinas como neosolaniol, toxina T-2 y toxina HT-2.

Toxicosis letales en Wisconsin que afectaron al ganado fueron producidas por consumo de forrajes que contenían Fusarium tricinctum. El agente responsable fue identificado como toxina $\mathrm{T}-2$. El cuadro clínico observado era de hemorragias extensivas de la superficie serosa de todas las vísceras internas.

La principal micotoxicosis humana reportada por este tipo de compuestos corresponde a Aleukia Tóxica Alimentaria, conocida también como ATA.<smiles>O=C(NC(Cc1ccccc1)C(=O)O)c1cc(Cl)c2c(c1O)C(=O)OCC2</smiles>

Se ha detectado en trigo, maíz, avena y centeno. Su acción tóxica en animales se manifiesta principalmente en el riñón. La susceptibilidad de do a la especie: patos, pollos y perros son los más afectados, mientras que los roedores y rumiantes (vacunos y ovinos) se presentan como los más resistentes. En patos, por ejemplo, la LD50 oral para ochratoxina A varía entre 135 y $170 \mathrm{ug} / \mathrm{ave}$, mientras que para ratas jóvenes ésta es de 20-22 $\mathrm{mg} / \mathrm{kg}$.

Se discutía su acción cancerígena, pero finalmente fue demostrada en ratas alimentadas con dosis de $40 \mathrm{ppm}$ de ochratoxina A durante 43 semanas, donde se observó desarrollo de tumores, tanto hepáticos como renales. los vertebrados a la ochratoxina $A$, varía de acuer- 


\section{CITRININA}

Es un compuesto con propiedades antibióticas y nefrotóxicas producido por varias especies de Penicillium y Aspergillus. Fue reconocido primeramente como un potente antibiótico, pero luego se encontró que producía graves daños renales en animales de experimentación, retardaba el crecimiento y eventualmente causaba la muerte.

Se ha comprobado su presencia en granos, especialmente cebada y en forrajes, asociada a la presencia de ochratoxina A. Esta asociación de las 2 nefrotoxinas ha llevado a suponer que se presentaría una acción sinérgica que se ha manifestado en nefropatías en cerdos. Su fórmula química se presenta en la Figura 7.

\section{Figura 7}

\section{Citrinina}<smiles>CC1=C(C(=O)O)C(=O)C(C)=C2C1=COC(C)C2C</smiles>

\section{RUBRATOXINAS}

El principal productor es Penicillium rubrum. Se ha aislado dos compuestos, rubratoxina $\mathrm{A}$ y rubratonina $B$, los cuales presentan estructura química similar, sólo difieren en que uno de los grupos anhidros de rubratoxina $B$ se encuentra reducido a lactol. Sus fómulas se señalan en la Figura 8.

La LD50 para rubratoxina A y B es de 6,6 y 3,0 $\mathrm{mg} / \mathrm{kg}$, respectivamente. $\bar{L}$ a rubratoxina $B$ posee efectos hepatotóxicos; además se ha demostrado su teratogenicidad por inoculación intraperitoneal en ratas de 8, 9 y 10 días de gestación. Algunos autores describen también algunos efectos mutagénicos.
Figura 8

Rubratoxina A<smiles>CCC(C)C1C2=C(CC(C3CC=CC(=O)O3)C3=C(C(=O)OC3=O)C(O)C1O)C(=O)OC2O</smiles>

Rubratoxina $\mathrm{B}$<smiles>CCC(O)C1C2=C(CC(C(O)C3CC=CC(=O)O3)C3=C(C(=O)OC3=O)C(O)C1CC)C(=O)OC2=O</smiles>

\section{GRISEOFULVIRA.}

Es producida por Penichlium janczewski (=Penicillium nigricans) P. griseofulvum, P. patulum, $\mathbb{P}$. albidum, $\mathbb{P}$. raciborshifl, $\mathbb{P}$. melínil, $\mathbf{P}$. urticae y otros. Esta sustancia antimicrobiana posee un valor único como agente terapéutico sistémico contra infecciones fíngicas cutáneas. A pesar de su efectividad clínica y la capacidad presente tanto en el hombre como en los animales, de tolerar dosis relativamente elevadas suministradas diariamente durante varias semanas, se ha debido restringir su.juso terapéutico debido a las respuestas de carácter tóxico observadas en los últimos años. Entre éstas se pueden mencionar lesiones a la piel, disturbios hematopoyéticos, 
manifestaciones neurológicas, alteraciones gastrointestinales, entre otras. 9.

Su estructura química se presenta en la Figura

Existe además información acerca de la formación de tumores al ser inyectada subcutáneamente en ratas jóvenes.

Figura 9

\section{Griseofulvina}<smiles>COc1cc(OC)c2c(c1Cl)OC1(C2=O)C(O)=CC(=O)CC1C</smiles>

\section{MICOTOXINAS TREMORGENICAS}

Este tipo de micotoxinas actúan a nivel del Sistema Nervioso Central. Incluyen varios compuestos que causan temblores en los animales infectados. Se han reportado sólo 10 compuestos tremorgénicos en la literatura, pero se han deter. minado las estructuras de 5 de ellos. Estos son verruculogenos TR-1 y TR-2, fumitremorgeno B, triptoquivalina y triptoquivalona.
Son producidos por hongos de los géneros Aspergillus y Penicillium y afectan de preferencia a los rumiantes en pastoreo; su efecto más común es la producción de temblores y en los casos más graves, hiperexitabilidad, convulsiones y muerte, aunque poco frecuente, no siendo posible observar lesiones durante la necropsia.

\section{MICOTOXINAS EN PRODUCTOS ALIMENTICIOS}

Son variadas las materias primas y productos alimenticios que pueden servir de vehículos en el desarrollo de un determinado cuadro clínico, debido a la presencia de estos metabolitos tóxicos.

\section{CEREALES}

Las posibilidades de desarrollo de los "hongos de campo" (Alternaria, Cladosporioum, Fusarium, Rhizopus, Chaetomium, Acremoníum, Helmintosporium) y "hongos del almacenamiento" (Aspergillus, Penicillium y Mucorales), tanto en materias primas como en productos elaborados en base a cereales, son bastante elevadas (Spicher, 1981).

Esto implica la eventual producción de metabolitos tóxicos en este tipo de producto, como se puede observar en la Tabla III.

Tabla III

Micotoxinas detectas en cereales

\begin{tabular}{|c|c|c|c|c|c|c|c|c|}
\hline Micotoxina & Trigo & Centeno & & Avena & Maíz & Arroz & Mijo & $\overline{\text { Sorgo }}$ \\
\hline Aflatoxina & $\mathrm{X}$ & & $\mathrm{X}$ & $\mathrm{X}$ & $\mathrm{X}$ & $\mathrm{X}$ & $\mathrm{X}$ & $\mathrm{X}$ \\
\hline Citrinina & $\mathrm{X}$ & $X$ & $\mathrm{X}$ & $\mathrm{X}$ & & & & \\
\hline Ac. Kójico & & & & & $\mathrm{x}$ & & & \\
\hline Ochratoxina & $\mathrm{X}$ & $\mathrm{X}$ & $\mathrm{X}$ & $\mathrm{X}$ & $\mathrm{X}$ & & & \\
\hline Patulina & $\underset{X}{X}$ & & & & & & & \\
\hline Sterigmatocistina & $\begin{array}{l}x \\
x\end{array}$ & & & & & $\mathrm{X}$ & & \\
\hline Zearalenona & $\hat{x}$ & & $\mathrm{X}$ & $X$ & $\mathrm{x}$ & $x$ & & X \\
\hline Tricotecenos & & $X$ & $\mathrm{X}$ & & $\mathrm{X}$ & & $\mathrm{X}$ & \\
\hline
\end{tabular}


Afiatoxina: constituye el principal tóxico detectado en este tipo de productos, elaborado especialmen. te por Aspergillus flavus. Datos de la literatura señalan que los productos más frecuentes de ser contaminados son maíz, cebada, avena, arroz, sorgo y trigo.

Con respecto al tipo de aflatoxinas, la que se presenta frecuentemente y en mayor concentración es la aflatoxina $B_{1}$, luego $G_{1}$ y por último $B_{2} y$ $G_{2}$, las cuales se encuentran sólo en pequenas cantidades. Existe además información acerca de la detección de aflatoxina $M_{1}$ en este tipo de productos, lo que llama la atención, ya que sólo se había detectado en productos animales como un derivado hidroxilado de la $\mathrm{B}_{1}$.
Se ha calculado que la tasa de infección de cereales con Aspergillus fiavus fluctúa entre el 10 y $60 \%$. Su desarrollo sin embargo, está condicionado a la presencia de algunos factores específicos, como por ejemplo la humedad; la cual debe ser de $18-19 \%$ ( $\pm 85 \%$ HR) para la producción del tóxico. Esta puede presentarse en maíz, lo que permitiría una rápida y considerable toxinogénesis. Junto a este factor, es necesario destacar la necesidad de contar también con condiciones óptimas de otros parámetros tales como temperatura, atmósfera, $\mathrm{pH}$, etc.

En la Tabla IV se presentan algunos datos de la presencia del tóxico en este tipo de productos y la concentración en que ellos han sido detectados.

Tabla IV

Presencia de aflatoxina $B_{1}$ en cereales y derivados

\begin{tabular}{|c|c|c|c|}
\hline País & Producto & $\begin{array}{l}\text { Muestras } \\
\text { contaminadas }\end{array}$ & $\begin{array}{l}\mathrm{B}_{1} \mathrm{ppb} \\
\text { (Promedio) }\end{array}$ \\
\hline Sudáfrica & Maíz & 2 de 52 & más de 1000 \\
\hline \multirow[t]{2}{*}{ Uganda } & Maíz & 19 de 48 & 133 \\
\hline & Sorgo & 16 de 69 & 152 \\
\hline Tailandia & Maíz & 22 de 62 & 265 \\
\hline \multirow[t]{2}{*}{ Filipinas } & Maíz & 95 de 98 & 110 \\
\hline & $\begin{array}{l}\text { Derivados } \\
\text { de maíz }\end{array}$ & 22 de 32 & 32 \\
\hline
\end{tabular}

Citrinina: su presencia en cereales ha sido demostrada al detectar en ellos concentraciones que fluctúan entre 0,07 y $80 \mathrm{ppm}$. Penicillium viridicatum parece ser la principal fuente de contaminación en trigo, cebada y avena y responsable de la producción del tóxico.

Ochratoxina: en la mayoría de los casos, la concentración en la cual se ha encontrado ochratoxina A en cereales fluctúa entre 0,2 y $0,5 \mathrm{ppm}$, lo que está bajo el límite crítico que causa problemas en aves y cerdos, pero en algunos casos, éste ha sido superado alcanzando valores de hasta 27,5 ppm.

Patulina: son pocos los reportes encontrados acerca de su presencia en cereales, aunque los hongos productores del tóxico se encuentran contaminando este tipo de productos. Algunos informes sin embargo, señalan casos en que se ha detectado en trigo y arroz (Frank, 1981a).
Sterigmatocistina: las especies toxinogénicas que se encuentran en cereales pueden llegar a producirla en concentraciones mayores a las que se podrían obtener en la producción de aflatoxinas. Esto significa un gran riesgo, pero en todo caso debe destacarse que es menos tóxica y carcinogénica que la aflatoxina $B_{1}$.

Existe poca información sobre una producción generalizada en cereales. Sólo se reportan casos aislados ocurridos en trigo $\mathrm{y}$ arroz.

Zearalenona: por ser Fusarium un contaminante habitual de granos, la presencia del tóxico es detectada en un gran número de cereales, en concentraciones variables que han llegado hasta 1700 ppm en ciertos tipos de maíz.

$\mathrm{Se}$ ha visto la influencia que ejerce el sustrato en la producción del tóxico por Fusarium roseum, logrando establecer que el mejor sustrato en el arroz refinado, seguido por maíz, trigo, arroz no refinado, cebada y avena. 
Tricotecenos: de las cerca de 40 toxinas de este tipo, la más frecuente de encontrar en cereales son la toxina $\mathrm{T} \cdot 2$, deoxynivalenol, nivalenol, monoacetoxyscirpenol y diacetoxyscirpenol.

De todos los cereales involucrados, el que presenta una contaminación más frecuente con este tipo de tóxico es el maíz, donde se han detectado concentraciones de hasta $2 \mathrm{ppm}$ para toxina $\mathrm{T} \cdot 2$; $1,8 \mathrm{ppm}$ para deoxynivalenol y $31,5 \mathrm{ppm}$ para diacetoxyscirpenol.

\section{FARINAEOS Y PRODUCTOS DE HORNEO.}

\section{FARINACEOS}

Existen datos aislados de la contaminación por micotoxinas de este tipo de productos. Frank detectó aflatoxina B1 en concentraciones de hasta $50 \mathrm{mg} / \mathrm{kg}$ en sémola y harina de trigo. Autores suizos reportan hasta $3 \mathrm{ppb}$ de aflatoxina en productos de maíz tales como sémola, polenta y almidón. Richardson en Inglaterra encontró en muestras de harina, ochratoxina A en concentraciones de hasta $6,25 \mathrm{ug} / \mathrm{kg}$.

\section{PRODUCTOS DE HORNEO}

El pan y otros productos horneados pueden llegar a contaminarse con micotoxinas de dos formas diferentes. La materia prima puede poseer hongos que elaboren la toxina, lo que constituiría la llamada contaminación primaria. La de tipo secundario se produciría por contaminación fúngica del producto ya horneado, donde existiría la posibilidad de elaboración del tóxico (Reiss, 1981a).

Aflatoxina: su presencia se ha detectado en varios tipos de productos horneados, siendo el más importante el pan, donde se ha encontrado hasta 54 y $186 \mathrm{mg} / \mathrm{kg}$ de aflatoxina $\mathrm{B}_{1}$ y $\mathrm{G}_{1}$, respectivamente.

La inquietud presentada hace bastante tiempo, acerca de la capacidad de difusión del tóxico en el pan, ha sido respondida por varios autores. No hay un acuerdo real en los resultados obtenidos, ya que algunos señalan que no hay difusión mientras que otros han detectado la toxina a $7 \mathrm{~cm}$ de profundidad, del lugar donde fue elaborada.

Patulina: al estudiar diferentes tipos de panes contaminados con hongos, Reiss (1972) encontró el tóxico en concentraciones de 0,1-0,3 mg/kg. Datos finlandeses señalan la presencia de patulina en pan en concentraciones de hasta $0,16 \mathrm{mg} / \mathrm{kg}$.
Sterigmatocistina: se la ha detectado en cantidades de hasta $0,4 \mathrm{ppm}$ en diferentes tipos de pan.

Ochratoxina A: en panes elaborados con harina de trigo y con centeno, y contaminados con AspergiIlus ochraceus, se detectó después de 34 días, hasta $385 \mathrm{mg} / \mathrm{kg}$ del tóxico.

Citrinina: Penicillium chrysogenum elaboró citrinina en diferentes tipos de panes, donde la mayor concentración fue de $0,4 \mathrm{mg} / \mathrm{kg}$, y se detectó en pan de tipo integral.

\section{MANI Y PRODUCTOS SIMILARES}

Son un buen sustrato para hongos productores de aflatoxinas. Los primeros ensayos comparativos fueron realizados por Frank (1966) y se presentan en la Tabla V.

\section{Tabla V}

Producción de aflatoxinas B1 y G1 $(\mathrm{mg} / \mathrm{kg})$ en maní y productos afines.

\begin{tabular}{lrrr}
\hline Producto & B1 & G1 & Total \\
\hline Maní tostado & 5 & 6 & 11 \\
Coco rallado & 100 & 75 & 175 \\
Manteca de maní & 50 & 30 & 80 \\
Semilla amapola & 100 & 60 & 160 \\
Avellanas & 5 & 60 & 65 \\
Almendras & 5 & 7,5 & 12,5 \\
Nueces & 5 & 60 & 65
\end{tabular}

Un problema general a considerar en este tipo de productos es el tipo de muestra a analiżar. En algunos casos se trata de productos molidos con cáscara, sin cáscara, parte sana del producto, parte dañada, mezcla de ambos, etc. Esto hace que no sea posible establecer una comparación de los resultados obtenidos por diferentes autores.

Es de interés constatar la presencia del tóxico en estos productos, ya que su consumo es bastante considerable. Se ha calculado que desde 1957, éste ha aumentado en regiones de climas templados desde valores de 0,5 a $2,6 \mathrm{Kg} /$ persona/año. 


\section{AVELLANAS}

Pareciera ser que la producción de aflatoxina en este tipo de productos es nula o sólo en muy pequenas cantidades (Frank,1981b). Sin embargo, estudios realizados por Senser (1979) han reportado concentraciones entre 300 y $1300 \mathrm{ug} / \mathrm{kg}$ de aflatoxina B1.

No existe información acerca de la producción de otras micotoxinas en avellanas.

\section{ALMENDRAS.}

Se ha detectado la presencia de aflatoxinas en almendras con y sin cáscara, tanto en países de Europa, como en EE.UU. En el producto molido, la situación es más delicada; estudios realizados en Suiza, demostraron que de 239 muestras analizadas, sólo 24 no presentaban el tóxico. De las muestras contaminadas más de un $50 \%$ sobrepasaba el límite de $10 \mathrm{ug} / \mathrm{kg}$ de aflatoxinas en general estipulado por la reglamentación local.

Sobre la producción de otras micotoxinas no existe información.

\section{MANI.}

Constituye el mayor riesgo de presencia de aflatoxinas a nivel mundial para la alimentación humana y animal. Aunque los problemas mayores provienen de regiones de Africa, Indonesia, India y Sudamérica, el maní cultivado y consumido en EE.UU. no deja de constituir un riesgo para la población.

La Tabla VI presenta datos del contenido de aflatoxinas en maní y productos derivados.

Tabla VI

Contenido de aflatoxinas en maní y productos derivados.

Número de muestras

\begin{tabular}{lccccr} 
Continente & Año & $>50 \mathrm{ug} / \mathrm{kg}(\%)$ & $5-50 \mathrm{ug} / \mathrm{kg}(\%)$ & $<$ <ug/kg(\%) $\begin{array}{r}\text { Total de } \\
\text { muestras }\end{array}$ \\
\hline \multirow{2}{*}{ Europa } & 1974 & $68(3,4)$ & $171(8,6)$ & $1744(88)$ & 1983 \\
& 1975 & $44(2,4)$ & $171(9,2)$ & $1641(88,4)$ & 1856 \\
Norteamerica & 1974 & $20(1,1)$ & $290(15,4)$ & $1568(83,5)$ & 1878 \\
& 1975 & $23(1,2)$ & $102(5,3)$ & $1800(93,5)$ & 1925 \\
Africa & 1974 & $63(2,1)$ & $91(3,0)$ & $2860(94,9)$ & 3014 \\
& 1975 & $61(3,2)$ & $104(5,4)$ & $1765(91,4)$ & 1930 \\
\hline
\end{tabular}

Otras micotoxinas han sido poco reportadas y no constituyen problemas considerables.

\section{NUEZ.}

Hay poca información al respecto, sólo algunos datos en EE.UU. donde detectaron concentraciones entre 2 y $70 \mathrm{ug} / \mathrm{kg}$ de aflatoxinas, mientras que en Alemania Federal se informa de 3 muestras con 1-4 ug/kg de 100 analizadas (Woller, 1981).

\section{CASTAÑAS DE CAJU.}

En Canadá se observó que de 120 muestras solamente 97 presentaban menos de $5 \mathrm{ug} / \mathrm{kg}$ de aflatoxinas en general. Sobre la presencia de otras micotoxinas no hay información.

\section{LECHE Y PRODUCTOS LACTEOS.}

La situación de la presencia de micotoxinas en leche y productos lácteos es problemática, ya que la contaminación puede producirse de diferentes maneras, tal como se señala en la Figura 10.

De acuerdo a un gran número de autores, en leche y productos lácteos, solamente podrían presentarse aflatoxinas. Existen sin embargo variadas opiniones, ya que las otras toxinas podrían presentarse por consumo de forraje contaminado 
(toxina T-2), o por ejemplo por formación de metabolitos de las aflatoxinas (sterigmatocistina, aflatoxicol).

En la Figura 11 de esquematiza en forma gene- ral la situación en este tipo de productos.

Es notable la importancia que reviste la presencia de aflatoxina $M_{1}$ en este tipo de productos. La Tabla VII presenta el contenido de ésta en diversos productos lácteos.

Figura 10

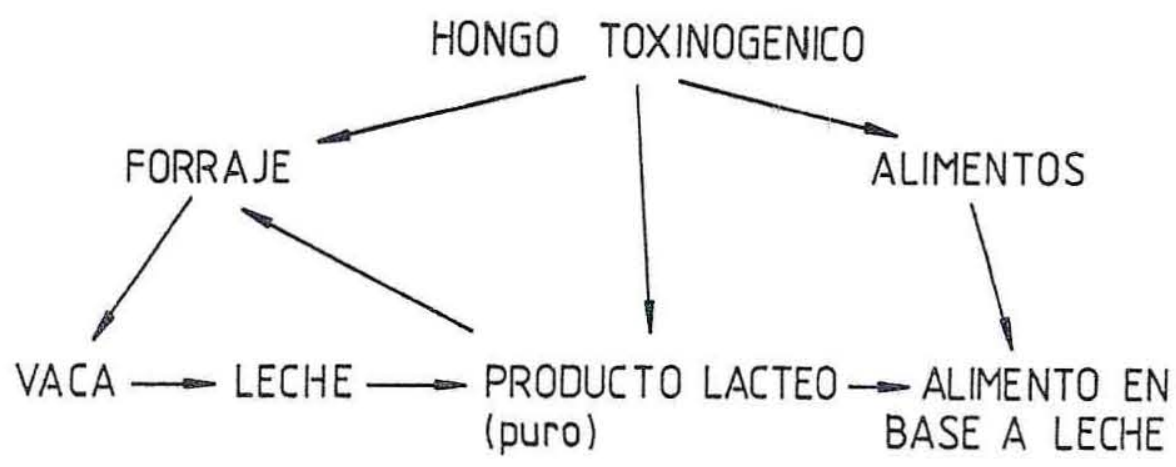

Tabla VII

Aflatoxina $\mathrm{M}_{1}$ en productos lácteos

\begin{tabular}{|c|c|c|c|c|c|c|c|c|}
\hline \multirow{2}{*}{$\begin{array}{l}\text { Producto } \\
\text { Leche en polvo }\end{array}$} & \multirow{2}{*}{$\begin{array}{l}\begin{array}{l}\text { № } \\
\text { Muestras }\end{array} \\
41\end{array}$} & \multirow{2}{*}{$\begin{array}{l}\begin{array}{l}\% \\
\text { positivas }\end{array} \\
73\end{array}$} & \multirow{2}{*}{$\frac{\text { min. }}{0,2}$} & \multirow{2}{*}{$\begin{array}{c}\frac{c}{\mathrm{Al}(\mathrm{ug} / 1)} \\
\text { máx }\end{array}$} & \multirow{2}{*}{$\frac{\vec{x}}{0,5}$} & \multicolumn{3}{|c|}{$\begin{array}{l}\text { Rangos de concentracio } \\
\text { nes (No de muestras) }\end{array}$} \\
\hline & & & & & & $\begin{array}{r}<0,2 \\
0,2-1,0 \\
1,0-2,0\end{array}$ & $\begin{array}{l}\mathrm{ppb} \\
\mathrm{ppb} \\
\mathrm{ppb}\end{array}$ & $\begin{array}{l}(11) \\
(24) \\
(6)\end{array}$ \\
\hline Yoghurt & 54 & 82 & 0,05 & 0,47 & 0,2 & $\begin{array}{r}<0,05 \\
0,05-0,20 \\
0,21-0,50\end{array}$ & $\begin{array}{l}\mathrm{ppb} \\
\mathrm{ppb} \\
\mathrm{ppb}\end{array}$ & $\begin{array}{l}(10) \\
(36) \\
(8)\end{array}$ \\
\hline Queso fresco & 80 & 34 & 0,10 & 0,51 & 0,23 & $\begin{array}{r}<0,1 \\
0,1-0,2 \\
0,21-0,5\end{array}$ & $\begin{array}{l}\mathrm{ppb} \\
\mathrm{ppb} \\
\mathrm{ppb}\end{array}$ & $\begin{array}{l}(53) \\
(13) \\
(14)\end{array}$ \\
\hline Camembert & 65 & 51 & 0,1 & 0,73 & 0,31 & $\begin{array}{r}<0,1 \\
0,1-0,5 \\
0,51-1,0\end{array}$ & $\begin{array}{l}\mathrm{ppb} \\
\mathrm{ppb} \\
\mathrm{ppb}\end{array}$ & $\begin{array}{l}(32) \\
(27) \\
(6)\end{array}$ \\
\hline Queso fundido & 134 & 40 & 0,1 & 0,55 & 0,26 & $\begin{array}{r}<0,1 \\
0,1-0,5 \\
0,51-1,0\end{array}$ & $\begin{array}{l}\mathrm{ppb} \\
\mathrm{ppb} \\
\mathrm{ppb}\end{array}$ & $\begin{array}{l}(81) \\
(51) \\
(2)\end{array}$ \\
\hline
\end{tabular}




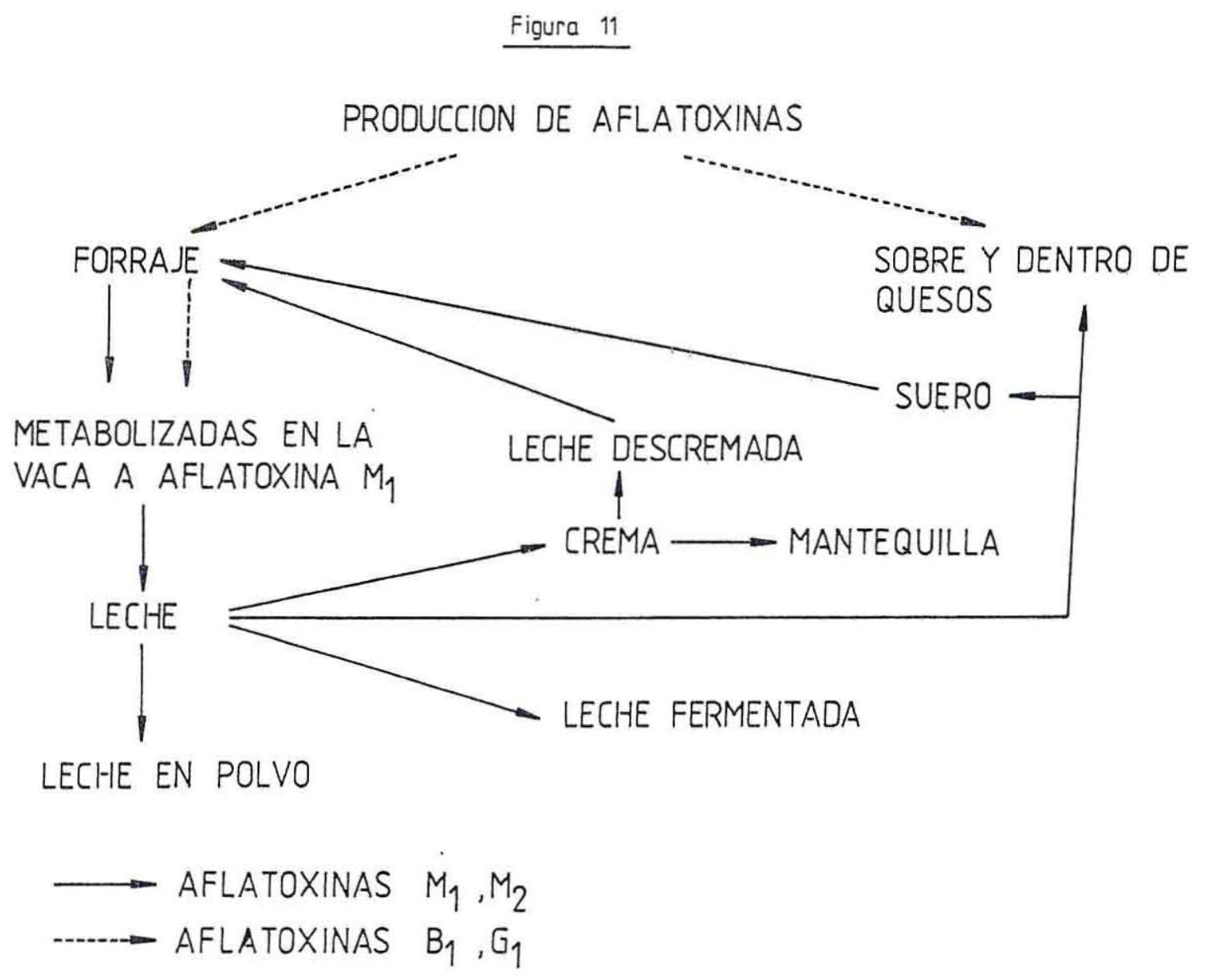

Según algunos autores, entre un 0,35 y un $1,5 \%$ de la aflatoxina ingerida por vacas, contenida en forrajes, se encuentra en la leche como $M_{1}$, que es tan tóxica como la $\mathrm{B}_{1}$. Se debería considerar inquietante en el caso de consumo de leche por infantes, los cuales son más susceptibles que los adultos. Sin embargo, se ha calculado que una criatura de $5 \mathrm{~kg}$ de peso debería absorver 27 litros de leche al día, si se tratara de leche de vacas que han sido alimentadas con $2 \mathrm{~kg}$ de tortas oleaginosas por día, conteniendo $4000 \mathrm{ppb}$ de aflatoxina $B_{1}$, para desarrollar síntomas iguales a los observadores en animales de experimentación, tomando en cuenta que sus susceptibilidades fueran semejantes (Mintzlaff, 1974).

\section{CARNE Y PRODUCTOS CARNEOS.}

Las micotoxinas pueden presentarse en la carne y productos cárneos. Las que se encuentran en el animal, generalmente provienen del consumo de forrajes contaminados; se depositan en órganos, carne y grasa, transformándose éstos en vehículos portadores del tóxico.

La contaminación fúngica de la carne no juega un papel muy importante en el problema de la elaboración de toxinas, pero sí debe considerarse el uso de carne, que contiene micotoxinas, en la producción de alimentos. No obstante, esta situación no reviste demasiada gravedad debido a que está presente el efecto de dilución del tóxico durante la elaboración del alimento.

Es muy común que haya una cierta contaminación fúngica postproceso, la cual puede desencadenar la producción de micotoxinas en el alimento. Especialmente peligroso es el caso de derivados cárneos madurados, como jamón crudo y salame, donde es frecuente el desarrollo de hongos en su superficie (Leistner, 1981). 
Tabla VIII

Producción de micotoxinas por inoculación experimental de hongos

\begin{tabular}{lll}
\hline $\begin{array}{l}\text { Micotoxina } \\
\text { detectada }\end{array}$ & $\begin{array}{l}\text { Hongo } \\
\text { inoculado }\end{array}$ & Productos en los que se detectó \\
\hline
\end{tabular}

Aflatoxina

Citreoviridina

Citrinina

Ochratoxina A

Patulina

Sterigmatocistina
Aspergillus flavus, Aspergillus parasiticus

Penicillium miczynskii

Penicillium viridicatum

Penicillium cyclopium,

Penicillium viridicatum,

Penicillium puberulum

Aspergillus ochraceus

Aspergillus versicolor
Carne molida (cerdo), carne de vacuno fresca, cecinas crudas, tocino, jamón cocido, jamón crudo.

\section{Cecinas crudas.}

Jamón crudo.

Cecinas crudas.

Jamón crudo, cecinas crudas.

Cecinas crudas, jamón crudo.

\section{MICOTOXINAS EN CARNE}

Aflatoxina: se ha reportado que cerdos alimentados con forrajes que contenían de 100 a $300 \mathrm{ppb}$ de B1 y sacrificados, acusaron presencia de residuos no superiores a $10 \mathrm{ppb}$. en órganos tales como hígado y riñones y siempre menos de $1 \mathrm{ppb}$ en los músculos.

Datos acerca de pollos broilers alimentados con alimentos contaminados con $100 \mathrm{ppb}$, señalan que se detectó en el hígado no más de $0,4 \mathrm{ppb}$ de $\mathrm{B}_{1}$ y en la musculatura no más de $0,3 \mathrm{ppb}$.

En huevos de gallinas alimentadas con dietas conteniendo $400 \mathrm{ppb}$ de $\mathrm{B}_{1}$ se detectó cantidades de 2 ppb (Mintzlaff, 1974).

Ochratoxina A: en cerdos se ha encontrado en concentraciones de 2 a $100 \mathrm{ppb}$, localizada en hígado, músculos y grasa. En aves se ha detectado en el hígado y músculos, pero no en huevos.

Toxina T-2: al alimentar aves con dietas conteniendo $15 \mathrm{ppm}$ del tóxico, se encontró después de 3 horas en el hígado, la toxina sin alteración visible; luego de $41 / 2$ horas no se detectó el tóxico. Esto se debería a la rápida reabsorción y metabolización que ésta presenta.

Zearalenona: no existe información de su presencia en el animal debido al consumo de dietas contaminadas.

\section{MICOTOXINAS EN PRODUCTOS CARNEOS.}

Numerosos estudios han sido realizados con el fin de conocer la incidencia de micotoxinas en productos cárneos. En la Tabla VIII se presentan algunos datos obtenidos por algunos autores.

De igual forma se ha estudiado la difusión del tóxico al interior de los productos. Es así como se ha detectado a $5 \mathrm{~mm}$ de profundidad las siguientes toxinas: citroviridina, ochratoxina A, rugulosina y sterigmatocistina.

En la República Federal de Alemania, donde se han realizado la gran mayoría de los estudios, no se ha detectado el tóxico en productos cárneos a la venta en el mercado. Es necesario sin embargo, continuar este tipo de controles, e implementarlos en el resto de los países, con el fin de tener plena certeza de que el problema de la presencia de micotoxinas no se presenta.

\section{OTROS PRODUCTOS ALIMENTICIOS.}

\section{FRUTAS}

Frutas de pepas y sus productos: la principal de este tipo es la manzana, sobre todo por su alto consumo. En ellas se han encontrado patulina en concentraciones de hasta $1,2 \mathrm{~g} / \mathrm{kg}$ de parte dañada y en jugo de manzana hasta 45 ppm (Frank, 1976; 1980c; 1981c). 
Frutas de hueso y sus productos: en duraznos y damascos se ha detectado hasta $120 \mathrm{mg} / \mathrm{kg}$ de patulina, observando además su difusión al tejido no dañado, en el caso de duraznos. En queques con frutas secas de diferentes tipos se ha reportado $40 \mathrm{ug} / \mathrm{kg}$ de $B_{1}$, pero no está claro si es debido a la fruta o a una contaminación de tipo secundario.

Otras irutas: bajas concentraciones de patulina han sido detectadas en plátanos, piñas, uvas, frutillas y tomates (Frank, 1977). En granadas contaminadas interiormente con hongos, se detectó hasta $50 \mathrm{ug} / \mathrm{kg}$ de $\mathrm{B}_{1}$.

\section{MERMELADAS Y MIEL}

No se ha detectado aflatoxinas en mermeladas de diferentes frutas, lo que es atribuído a su elevado contenido de azúcar (60\%). La misma situación se ha presentado en el caso de la miel.

\section{BEBIDAS ALCOHOLICAS.}

Experiencias realizadas en Canadá demostraron la presencia de patulina en diferentes cepas de uva, pero no en el vino elaborado con ellas. Con respecto a la presencia de aflatoxinas, existen diferentes opiniones, algunas acusan su presencia, otras no; se postula en algunos casos que en el vino blanco no se produciría, pero sí en el vino tinto, etc.

En cerveza, elaborada en forma adecuada, no se ha logrado detectar la presencia de micotoxinas, lo cual difiere con la idea teórica de que este tipo de bebida sería más susceptible a la contaminación que el vino (Woller, 1982).

\section{CONDIMENTOS}

Debido a la gran frecuencia con que se presentan hongos, que potencialmente serían de carácter toxigénico, se ha investigado la presencia de aflatoxinas en este tipo de producto. Los resultados no muestran una línea muy bien definida, obteniéndose grandes diferencias de acuerdo al origen de la especia analizada. Al estudiar 24 muestras de pimienta blanca y negra no se obtuvo resultados positivos. Ensayos efectuados en paprika y otros similares como pimienta cayena de India, demostraron la presencia de 14 muestras de 33 casos analizados. Estos contenían entre 2 y 0 $u g / \mathrm{kg}$ de aflatoxina, mientras que al analizar 30 muestras del mismo producto, pero proveniente de Singapur no se detectó el tóxico (Frank, 1981d). La nuez moscada pareciera ser un buen sustrato para la producción de aflatoxinas, pero los niveles alcanzados son generalmente de valores bajos los $25 \mathrm{ug} / \mathrm{kg}$. Sin embargo, como esta especie es incorporada a los alimentos en concentraciones no mayores al $1 \%$, la cantidad de aflatoxina máxima que podría encontrarse en el producto final sería bastante baja, $25 \mathrm{ug} / 100 \mathrm{~kg}$ (ICMSF, 1980).

No se ha detectado la presencia de otras micotoxinas, como ochratoxina A y sterigmatocistina en este tipo de productos (Miajerus, 1985).

\section{MICOTOXICOSIS}

Son variadas las patologías producidas por consumo de alimentos contaminados por metabolitos secundarios tóxicos de carácter fúngico. A estas alteraciones se las ha denominado micotoxicosis, término introducido en 1962 por Forgacs y Carll, quienes lo definieron como la "intoxicación del huésped como consecuencia de la entrada al cuerpo de una sustancia tóxica de origen fúngico". Este término está limitado a aquellas entidades patológicas asociadas con la ingestión de alimentos o forrajes, en los cuales el hongo prolifera y origina productos de carácter tóxico. Aunque la intoxicación debida a la ingestión de ciertos Basidiomycetes, hongos superiores o callampas, debería ser incluída en este contexto, es tratada en forma separada (Graham, 1980).

\section{MICOTOXICOSIS EN ANIMALES.}

El problema en países europeos, especialmente en cerdos, es de importancia sobre todo por las grandes pérdidas que ha ocasionado. Responsable principal es la presencia de algunas especies de Fusarium capaces de elaborar toxinas. Se ha comprobado que la difusión de las toxicosis producidas por Fusarium tiene relación directa con el aumento del cuitivo de maíz híbrido madurado en forma tardía. Su contaminación por este tipo de hongo es frecuente, lo que hace posible la producción de toxinas ya que se presentan también condiciones óptimas para la toxinogénesis.

En general, las micotoxicosis pueden presentarse tanto en forma aguda como crónica.

Una toxicosis aguda se presenta como consecuencia inmediata a la ingestión de una gran dosis de toxina. Los síntomas clínicos de una enfermedad aguda son bastante típicos para cada micotoxicosis, pero de todas maneras presentan mayor dificultad de ser diagnosticados que los de una intoxicación de carácter crónico. La detección de la toxina a nivel de laboratorio es necesaria, aún 
en estos casos agudos, ya que por no haber medidas terapéuticas específicas para las micotoxicosis, sólo el alivio de los síntomas es posible.

Una micotoxicosis crónica se produce cuando el animal ingiere la toxina en pequeñas cantidades y durante un período de tiempo prolongado. Los síntomas clínicos son en la mayoría de los casos poco específicos y por lo tanto difíciles de identificar. A menudo se aprecian transtornos relacionados con pérdida de peso, fertilidad, disminución de la capacidad de producir leche o de poner huevos, en el caso de las aves. Como consecuencia puede desencadenarse una infección bacteriana secundaria en forma de septicemia y en casos más extremos una inmunosupresión, ya que la mayoría de las micotoxinas inhiben el desarrollo de la actividad inmunitaria.

\section{FUSARIOTOXICOSIS.}

Las cepas que presentan la mayor toxicidad pertenecen al grupo de Fusarium tricinctum, F. sporotrichiodes, F. poae y $\mathrm{F}$. nivale, elaboradores de tricotecenos. Representantes del grupo F. roseum, como F. graminearum, F. culmorum y F. sambucinum producen la toxina estrogénica zearalenona (Frank, 1979).

Cerdos: los primeros casos detectados en EEUU (1928) y en Alemania (1929) fueron debidos al consumo de forrajes contaminados con Fusarium graminearum. Los síntomas principales observados fueron vulvovaginitis ocasionadas por la micotoxina zearalenona (toxina F-2). Este sindrome estrogénico comenzó a ser observado posteriormente en casi todos los países europeos.

La gravedad de los síntomas va a depender de la cantidad del tóxico ingerido. En las hembras, la inflamación de la vulva comienza al tercer día luego de la ingestión del forraje contaminado o aún antes, siendo bastante considerable al cabo de algunos días. Este edema ocasionado puede tener también efecto por contacto directo,tanto en los genitales del macho como en el recién nacido. Además del edema vulvar puede presentarse un engrosamiento del útero,en algunos casos 3 a 4 veces el tamaño normal. El tóxico puede ser metabolizado a beta-zearalenol y transmitido por la leche a los recién nacidos, que en el caso de las hembras desarrollan la inflamación vulvar.

Este cuadro generalmente es acompanado por vómitos (10 a 45 minutos después de la ingestión del tóxico) y disminución del consumo de forrajes.

La fusariotoxicosis en cerdos presenta también una forma letal, por inflamación del estómago e intestino, producida por tóxicos de Fusarium sporotrichioides y $F$. poae.
Vacunos: en la literatura especializada se han descrito 3 formas de fusariotoxicosis en vacunos.

En Rusia, por consumo de forrajes contaminados con Fusarium sporotrichioides se han producido casos fatales. Se caracteriza por transtornos motores, digestivos, aborto $\mathrm{e}$ inflamaciones hemorrágicas en estómago e intestino.

En EE.UU., el consumo de rorraje contaminado con $\mathbf{F}$. tricinctum ha provocado cuadros caracterizados por pérdida de peso, necrosis dérmica, hemorragias y necrosis en órganos internos. Se ha atribuído a toxina T-2 y butenolida.

En Inglaterra, zearalenona producida por $\mathbf{F}$. graminearum, ha ocasionado casos de infertilidad.

\section{AFLATOXICOSIS.}

Reviste una gran importancia, sobre todo por la presencia del tóxico en productos en base a maní, principalmente proveniente de países con climas tropicales.

Aves: las manifestaciones de la aflatoxicosis en aves incluye una depresión del crecimiento, menor eficiencia de conversión, despigmentación, alteración de la producción de huevos y de la calidad de las cáscara, un aumento del decomiso de broilers en el matadero, mortalidad y una respuesta inmunitaria disminuida. El hígado constituye el órgano blanco, donde se presentan lesiones macro y microscópicas, aumento en peso y de la concentración de lípidos y modificación de la composición de ácidos grasos. Estas toxinas estimularían la actividad de enzimas lizosomales del hígado y tejido muscular, lo que determinaría una gran fragilidad capilar. El sistema inmune también es altamente sensible al efecto tóxico, produciendo inmunodepresión que afecta la resistencia natural a infecciones.

Cerdos: el tóxico no parece tener efecto en la reproducción porcina a niveles que induzcan efectos clínicos. Por ser inmunodepresoras ejercen un fuerte efecto sobre la resistencia natural y adquirida en el cerdo. Todas las funciones de inmunidad celular y humoral son deprimidas. Reduce la absorción de proteínas, ácidos grasos, vitaminas $\left(\mathrm{D}_{3}, \mathrm{~K}, \mathrm{E}\right.$, complejo $\left.\mathrm{B}\right)$ y minerales $(\mathrm{Fe}, \mathrm{Cu})$.

A la necropsia pueden encontrarse ictericia, ascitis y un hígado pálido anaranjado. En casos agudos pueden presentarse descargas rectales sanguinolentas y convulsiones.

Bovinos: son más resistentes que otros animales a los efectos de aflatoxinas, por lo que son comparativamente escasas las descripciones de aflatoxicosis bovinas naturales. 
Como en otras especies, producen daño hepático progresivo. Este puede detectarse hasta 3 a 5 semanas después de haber cesado la ingestión del tóxico. El transtorno hepático ha sido provocado por niveles de aflatoxina en el alimento no menores a $100 \mathrm{ng} / \mathrm{g}$, ordinariamente coincidentes con síntomas inespecíficos (deficiente desarrollo en terneros, insuficiente ganancia de peso en animales de engorda, anorexia, letargia, descenso en la producción en vacunos lecheros).

Evidencias empíricas señalan efecto abortígeno de aflatoxina $\mathrm{B}_{1}$, lo que no ha sido demostrado experimentalmente. Sin embargo, al administrarla a vacas gestantes, su presencia ha sido demostrada en la placenta y en el hígado fetal (Parada, 1986).

\section{TOXICOSIS A TRAVES DE PENICILLIUM VIRIDICATUM (NEFROPATIA MICOTOXICA).}

Cerdos: en los últimos años se presentó en Dinamarca casos de cuadros renales en cerdos alimentados con forrajes contaminados con Penicillium viridicatum y $\mathbf{P}$. cyclopium. Las micotoxinas ochratoxina A y citrinina fueron los agentes responsables identificados. Casos similares se han reportado en Noruega, Suecia e Irlanda.

El cuadro clínico de la intoxicación presenta en primer lugar una sed intensa lo que implica un aumento en el consumo de agua y en la producción de orina. Se presentan cambios regresivos en el epitelio tubular así como también lesiones que van desde fibrosis periglomerulares hasta atrofia tubular (Palyusik, 1981).

Aves: también presentan daños renales. Se ha detectado ochratoxina A en riñones, hígados y músculos en concentraciones de hasta $50 \mathrm{ug} / \mathrm{kg}$.

\section{TOKICOSIS TREMORGENICAS}

Afectan de preferencia a los rumiantes en pastoreo; su común denominador es la producción de temblores. Se han reportado cuadros tremorgénicos convulsivos mortales, acompañados de fenómenos hemorrágicos y degeneración en masas musculares, ocurridos en Sudáfrica por el desarrollo de Aspergillus clavatus en maíz y orujo de cervecería, hongo del cual no se ha aislado ninguno de los tremorgenos hasta ahora conocidos.

Es teóricamente posible que la ingestión de suelo rico en hongos tremorgénicos, o que la absorción de las toxinas por la planta, pueda explicar los fenómenos tremorgénico-convulsivos a veces provocados por plantas forrajeras como el pasto Bermuda o chépica (Cynodon dactylon). También tales mecanismos, así como la eventual participación de hongos endófitos, podrían explicar la producción de dichos fenómenos por algunos coirones (Festuca spp) en Chile y Argentina; el tema es sin embargo conjetural (Parada, 1986).

\section{ERGOTISMO}

El ergotismo bovino ocurre de preferencia al consumirse las plantas en pie; la mayor frecuencia de casos ocurridos durante los últimos 20 años en el mundo se asocia al consumo de ballica perenne y pastn Bermuda afectado con Claviceps purpurea.

La forma convulsiva es poco frecuente en vacunos, sin embargo se ha reportado un caso masivo en Yugoeslavia. La forma gangrenosa ocurre de preferencia en bovinos que pueden perder una o más extremidades, orejas y cola por gangrena seca, generalmente complicada por infección secundaria. Por otra parte, evidencias clínicas señalan abortos en el ergotismo bovino, aunque ello no ha sido comprobado experimentalmente; el aborto es característico de la enfermedad en las ovejas.

\section{MICOTOXICOSIS HUMANAS}

De acuerdo a numerosos informes de estudios realizados a nivel mundial se están aclarando las dudas existentes, de si era posible que la presencia de micotoxinas en alimentos tuviera algún efecto en el hombre. El mayor peligro lo constituye el uso de materias primas contaminadas en la elaboración de productos alimenticios.

\section{AFLATOXICOSIS}

\section{Intoxicación aguda}

La posibilidad de que se presente este tipo de alteraciones no es demasiado elevada. Se ha calculado por ejemplo que en Africa se deberían consumir $16 \mathrm{~kg}$ de maní altamente contaminado, en cada comida, para que se presentara una intoxicación aguda. Esto es muy poco probable. A pesar de, ésto existen informes (van Walbeck y col., 1968) sobre alteraciones digestivas graves en pacientes canadienses por consumo de pasteles de carne y spaghetti, en los cuales se aisló hongos aflatoxinogénicos. En Uganda se observaron necrosis centrilobulares en el hígado de un joven 
muerto; al analizar restos de la comida ingerida se constató una contaminación extraordinariamente alta de aflatoxina, $1,7 \mathrm{mg} / \mathrm{kg}$.

En el Instituto de Higiene de la Universidad de Münster, Bösenberg (1972) pudo por primera vez establecer una relación entre la ingestión de aflatoxinas con el desarrollo de una enfermedad grave. Un paciente muerto, con distrofia hepática, había consumido previamente una considerable cantidad de nueces. Al analizar éstas, se detectaron 3 tipos de hongos aflatoxigénicos. $\mathrm{La} \mathrm{B}_{1}$ fue a la vez detectada en un extracto del hígado del fallecido.

\section{Intoxicación crónica}

Cáncer hepático: son bastantes los informes relacionados con el desarrollo de carcinoma hepático primario, no producido por metástasis, asociado al consumo de productos contaminados con aflatoxinas. En especial son casos detectados en países como Sudáfrica, Uganda, Tailandia, Filipinas, Swazilandia y Kenia, en general regiones con climas tropicales.

Se han recopilado resultados de estudios epidemiológicos en diversos países en forma estadística y se observó que existe un alto grado de correlación entre la ingesta diaria de aflatoxina y la frecuencia de aparición de cáncer hepático primario, como se observa en la Figura 12

\section{Figura 12}

Relación ingesta diaria de aflatoxinas - frecuencia aparición carcinoma hepático

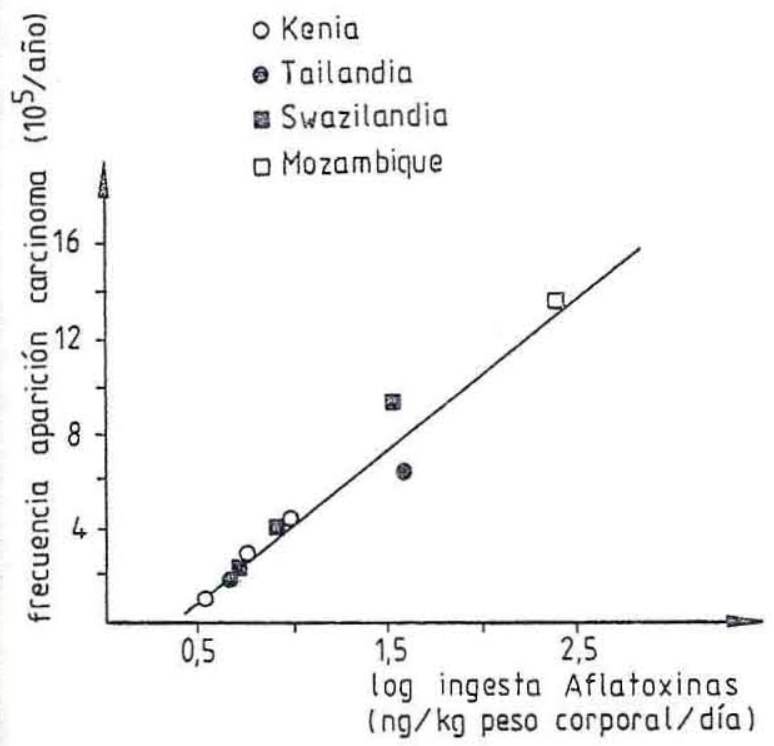

En todas las regiones estudiadas los alimentos involucrados eran principalmente maní y maíz. A pesar de los datos obtenidos, no se ha logrado unificar los criterios en relación a esta combinación ingesta del tóxico desarrollo de carcinomas. Se postula en algunos casos, que por lo menos en regiones al sur del Sahara, existiría la participación de un virus oncogénico, además de la aflatoxina en el desarrollo del cuadro canceroso (Reiss, 1981b).

Cirrosis hepática y hepatitis: la cirrosis infantil que se presenta en la India pertenece a un tipo de enfermedades bastante poco comunes y que se encuentra circunscrita a determinadas regiones. Se debería a una serie de factores, entre los cuales se postula a la acción de aflatoxinas. Se supone que posiblemente se presenta en niños cuyas madres han consumido durante el embarazo, maní altamente contaminado con el tóxico.

También en India, se presentaron casos fatales de hepatitis por consumo de maíz contaminado con el tóxico. Este se detectó tanto en el alimento como en la sangre de los pacientes.

Cáncer pulmonar: en Checoeslovaquia se reportó la muerte de un individuo, debida a un tumor pulmonar. Este trabajó durante 3 meses en un proceso destinado a esterilizar harina de maní de procedencia brasileña, contaminada con Aspergillus flavus. En el tejido pulmonar fue posible detectar la presencia de aflatoxina B1.

Sindrome de Reye: existen también evidencias que un cuadro clínico en Tailandia conocido como Síndrome de Reye, encefalopatía de Udorn o encefalopatía y degeneración grasa de víscera (EFDV), puede ser asociada con aflatoxicosis humana. La enfermedad se caracteriza por vómitos, convulsiones, coma y muerte; en la autopsia se detecta edema cerebral y acumulación de grasa en el hígado, riñón y corazón. La intoxicación con aflatoxinas se sugirió como una posible causa, ya que los síntomas de EFDV en humanos eran muy similares a los cbservados en aflatoxicosis agudas en monos.

En una ocasión, el consumo de arroz contaminado en Tailandia fue asociado con un caso de EFDV. En estudios posteriores, se demostró la presencia de altos niveles de $\mathrm{B} 1$ en vísceras en 22 de 23 casos fatales de EFDV, mientras que se observó sólo bajos niveles de aflatoxina al efectuar la autopsia. Se debe hacer presente que en EE.UU. los residuos de aflatoxina no han sido asociados al síndrome de Reye, sino que se le atribuye a una acción de carácter viral (Riemann y Bryan, 1979). 


\section{FUSARIOTOXICOSIS}

Enfermedad de Kashin-Beck: desde el siglo pasado se conoce esta osteoartrosis deformante en el este de Rusia, China del Norte y Corea del Norte. Afecta especialmente a niños donde se produce artritis; alteraciones en el crecimiento y danos degenerativos a la estructura ósea. Responsable de esta intoxicación ha sido el Fusarium sporotrichioides, transmitido por cereales.

Aleukia Tóxica Alimentaria (ATA): fue reportada en Rusia en 1913, alcanzando proporciones de epidemia durante la segunda guerra mundial y en años de la post guerra (1942-1947). La afección era causada por la ingestión de granos de cereales, particularmente mijo y trigo, que habían permanecido durante el invierno en los campos y que formaban parte de la dieta de la población rural rusa durante ese período. El cuadro clínico pro. ducido se caracterizaba por alteraciones patológicas en el sistema hematopoyético, lo cual se reflejaba en una atrofia total de la médula ósea, incluyendo agranulocitosis, angina necrótica y sepsis. La mortalidad fluctuaba: entre un 2 y un $80 \%$, dependiendo de la cantidad de toxina ingerida y del estado nutricional del individuo. Los metabolitos tóxicos involucrados en este caso son la toxina $\mathrm{T}-2$ y otras.

Daños a la piel: todas las toxinas del tipo tricotecenos producen daños a la piel. Se han descrito éstas junto con alteraciones oculares, abscesos subcutáneos y encefalopatías en niños por infección con Fusarium solani.

Enfermedad de Akakabi: después de la segunda guerra mundial, apareció en Japón una intoxicación por consumo de alimentos, caracterizada por náuseas, vómitos, diarrea, dolores de cabeza y cólicos. Se la denominó enfermedad de akakabi (hongo rojo) y era producida por Fusarium graminearum y $\mathbb{F}$. nivale a través de toxinas, probablemente del tipo tricotecenos.

Cáncer: algunos tricotecenos, toxina T-2 especialmente, han sido responsables de producir tumores en tracto gastrointestinal del hombre y animales.

Nefropatía endémica de los Balcanes: en Yugoeslavia, Rumania y Bulgaria se han presentado casos de enfermedades renales, caracterizadas por destrucción de los túbulos y fibrosis capsular. Se atribuyó, en un comienzo, a la acción de virus o metales pesados del suelo, hastá que se vio que era debido a la presencia de una micotoxina. Se ha estudiado bastante al respecto y se cree que podría ser ochratoxina A transmitida por consumo de carne de cerdo contaminada.
Beriberi cardíaco: es una enfermedad extremadamente severa que se ha reportado en varios países consumidores de arroz, durante los tres últimos siglos. Se la denomina así por los síntomas cardíacos y por la creencia

que una avitaminosis era la causa de su manifestación. Sin embargo, estudios epidemiológicos efectuados por investigadores japoneses sugirieron tratarla como una micotoxicosis posiblemente debida a la ingestión de arroz contaminado con Penicillium citroviride.

Se caracteriza por atacar el sistema nervioso central progresando desde vómitos y convulsiones a parálisis ascendente y paro respiratorio. Generalmente se torna fatal dentro de tres días. Los síntomas cardíacos incluyen irritabilidad, palpitaciones, dilatación del ventrículo derecho y otros. $\mathrm{Se}$ ha demostrado que existe un factor estacional de la enfermedad; la incidencia aumentada en el período húmedo de principios de verano y finales de otoño, sugeriría así la participación de una micotoxina.

\section{MEDIDAS ADOPTADAS FRENTE AL PROBLEMA}

\section{REGLAMENTACION}

Ante la evidencia cada vez mayor de cuadros clínicos producidos por la ingestión de alimentos y forrajes contaminados con el tóxico, tanto diversos organismos internacionales (FAO, OMS, UNICEF, entre otros), como cada uno de los países afectados, reglamentaron sobre el contenido máximo de las diferentes toxinas en los productos alimenticios.

En 1966, el PAG (Protein Advisory Group), organismo patrocinado por FAO, OMS y UNICEF, estableció que el nivel máximo permitido de aflatoxinas en general, en los diferentes productos alimenticios, tanto para el hombre como para los animales, era de $30 \mathrm{ppb}$.

En la Tabla IX se presentan los límites establecidos por diferentes países con respecto al contenido máximo de aflatoxinas en alimentos, tanto destinados al consumo humano como animal.

En la Tabla $X$ se presentan los límites máximos permitidos en algunos países para otras micotoxinas. 
Tabla IX

Límites máximos permitidos de aflatoxinas

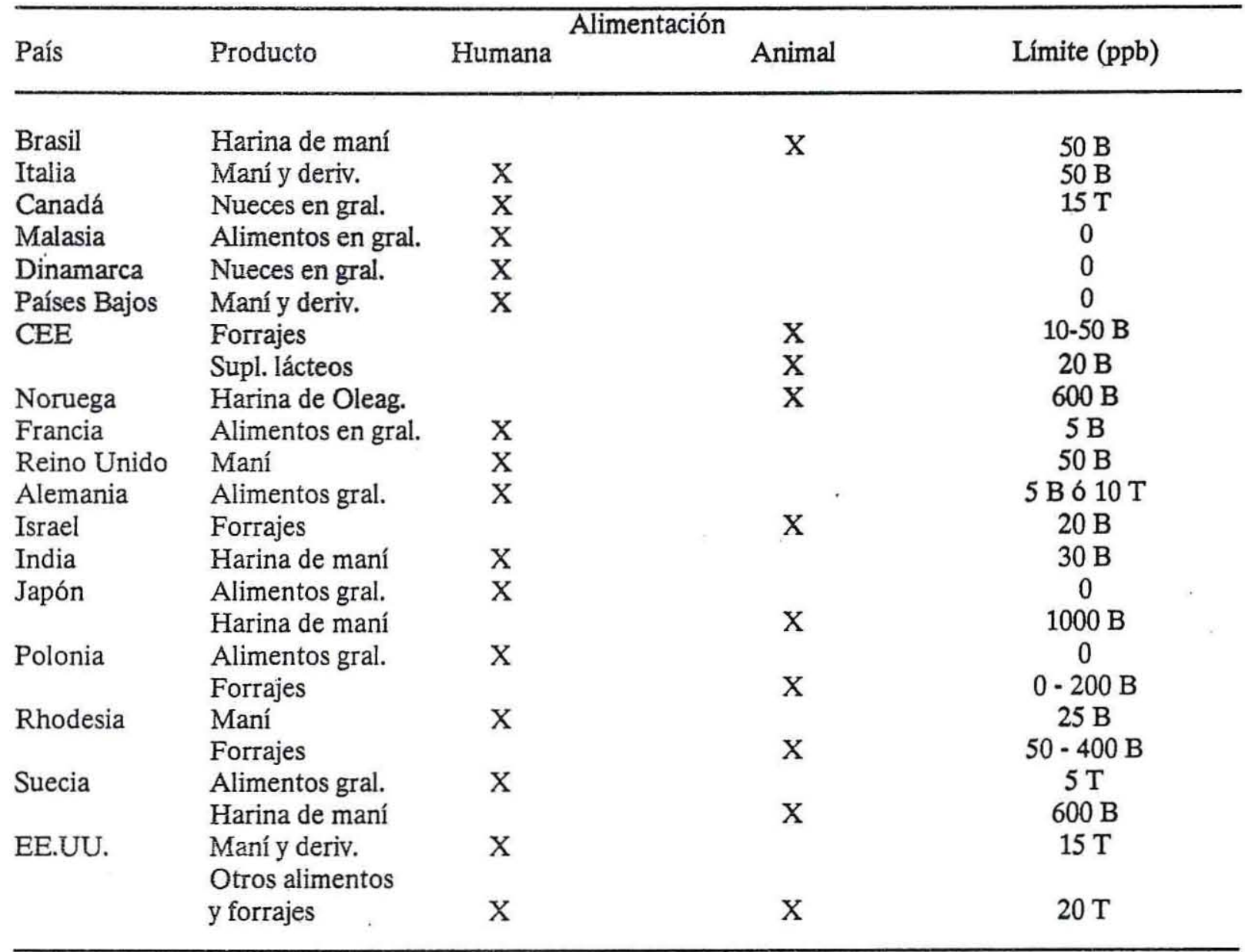

$\mathrm{B}=$ aflatoxina $\mathrm{B} 1 \quad \mathrm{~T}=$ Aflatoxina en general

$\mathrm{CEE}=$ Comunidad Económica Europea

\section{DETOXIFICACION}

Una vez que el alimento está contaminado con el tóxico, existen dos posibles acciones que permitirían su posterior utilización: la remôción de la toxina o la degradación de ella a compuestos menos tóxicos o no tóxicos.

La primera posibilidad se puede realizar sólo cuando la toxina esté presente en unidades del alimento que puedan ser identificadas y luego removidas del resto del lote, o cuando se pueda utilizar un solvente para extraer la toxina sin que éste deje unidades dañinas o que alteren el alimento (Marth y Doyle, 1979; Diener, 1981). La segunda opción se podría llevar a cabo usando métodos físicos, químicos y biológicos.

\section{Métodos ñ́sico-químicos.}

Separación mecánica: se ha visto su efectividad en productos donde es posible observar las unidades dañadas. En maní se ha logrado disminuir los valores de aflatoxina de $150 \mathrm{a} 3 \mathrm{ug} / \mathrm{kg}$. En frutas bastaría retirar la parte dañada, siempre y cuando existiera la completa certeza de que el tóxico no es capaz de difundir al tejido sano.

Prensado, centrifugado, adsorción y filtración: ha dado buenos resultados en productos como aceite y semillas oleaginosas.

Extracción: lavados realizados con agua pura o adicionada de sales, como así también el uso de solventes puros o en mezcla han permitido extraer gran parte de la contaminación presente. 
Tabla X

Límites máximos permitidos para otras micotoxinas

\begin{tabular}{|c|c|c|c|}
\hline$\overline{\text { País }}$ & Producto & Micotoxina & Tolerancia (ppb) \\
\hline \multirow[t]{4}{*}{ Bélgica } & Todo alimento & Patulina & 0 \\
\hline & Todo alimento & Ochratoxina A & 0 \\
\hline & Todo alimento & Sterigmatocistina & 0 \\
\hline & Todo alimento & Zearalenona & 0 \\
\hline \multirow[t]{2}{*}{ Dinamarca } & Carne cerdo & Ochratoxina A & 25 \\
\hline & Hígado y riñón de cerdo & Ochratoxina A & 10 \\
\hline \multirow[t]{2}{*}{ Noruega } & Concentrado de & & \\
\hline & manzanas & Patulina & 50 \\
\hline \multirow[t]{2}{*}{ Suecia } & Concentrado de & & \\
\hline & manzana & Patulina & 50 \\
\hline Suiza & Jugo manzana & Patulina & 50 \\
\hline Canadá & Todo cereal & Deoxinivalenol & 0 \\
\hline \multirow[t]{2}{*}{ Rusia } & Todo alimento & Patulina & 5 \\
\hline & Todo alimento & Ochratoxina A & 5 \\
\hline
\end{tabular}

Calentamiento: en general las aflatoxinas puras y deshidratadas son estables al calor hasta alcanzar su punto de fusión. La presencia de agua favorece la destrucción por aplicación de un tratamiento térmico. Patulina también presenta una marcada termorresistencia, que varía de acuerdo al $\mathrm{pH}$ del medio en el que se encuentra. Existen diversos ensayos realizados donde se observan resultados positivos en varios productos alimenticios.

Radiaciones: las aflatoxinas son sensibles a la luz UV. No es un método práctico debido a la poca penetración de la luz y a los cambios autooxidativos producidos en el sustrato, lo que afecta las características organolépticas del producto. Lo mismo podría ser válido para el uso de otras radiaciones ionizantes, sin embargo este método podría ser efectivo al utilizarlo en combinación con otro procedimiento detoxificante. Otras toxinas presentan sensibilidad a la luz, como por ejemplo ochratoxina A y citrinina.

\section{Métodos químicos}

Oxidantes: productos tales como $\mathrm{NaClO}, \mathrm{H}_{2} \mathrm{O}_{2}$ y ozono han demostrado ser bastante efectivos en la degradación de micotoxina.

Acidos: transforman las aflatoxinas $B_{1}$ y $G_{1}$ en $B_{2 a}$ y $\mathrm{G}_{2 \mathrm{a}}$, respectivamente, con lo que se logra dismlnuir su efecto tóxico: Patulina sin embargo, presenta una elevada estabilidad frente a medios ácidos.

Alcalis: las aflatoxinas son sensibles a su acción. Utiles para este efecto son el $\mathrm{NaOH}$ y amoníaco. Esto puese ser aplicado también para el caso de patulina.

Bisulfito, $\mathrm{SO}_{2}$ y otros: han demostrado ser eficaces en la đetoxificación de varios productos alimenticios.

\section{Métodos biológicos.}

Existe una gran variedad de microorganismos que poseen la capacidad de degradar aflatoxinas, 
como por ejemplo Flavobacterium auriantacum, Aspergillus niger, Penicilliun raistrickii, Aspergillus terreus, A. luchensis, Nocardia asteroides, Scopulariopsis brevicaulis, Rhizopus oryzae, Corynebacterium rubrum, Trichoderma viride, Mucor ambiguus, Helmintosporium sativum, Mucor griseo-cyanus, Absidia repens, Mucor alternans, Aspergillus parasiticus y levaduras.

No se conoce bien el mecanismo por el cuál se produce la degradación. Algunos autores postulan una acción enzimática, otros una acción química, no enzimática ni específica.

Se puede lograr también una inactivación por efectos combinados, por ejemplo patulina reacciona con grupos - $\mathrm{SH}$ del sustrato y se inactiva por alcalinización progresiva debida a autolisis.

Es necesario continuar con esta línea de investigación con el fin de dar solución a algunos problemas que pueden presentarse al realizar el proceso de detoxificación, tales como a) cualquier tratamiento químico o físico para remover micotoxinas debe ser sumado al costo del producto ya afectado por crecimiento fúngico; además del costo del proceso inicial, puede haber pérdidas de material adicional al efectuar la separación de las partes infectadas con micotoxinas, ya sea en forma mecánica o químicas (extracción con solventes); b) la mayoría de los procesos que remueven micotoxinas no son $100 \%$ eficientes; c) al utilizar un proceso químico, se requiere un control extensivo para tener la seguridad que no se ha formado un compuesto secundario biológicamente activo con un modo de acción diferente, y d) los procesos utilizados en la remoción de micotoxinas pueden inducir a una disminución del valor nutritivo del producto final (Beuchat, 1978)

\section{SITUACION ACTUAL DEL PROBLEMA EN CHILE.}

En el año 1986 se llevó a cabo en la Estación Experimental de La Platina, el "Encuentro Nacional sobre Micotoxinas y Micotoxicosis en el Sector Agropecuario" organizado y auspiciado por el Instituto Nacional de Investigaciones Agropecuarias INIA y el Proyecto INIA-PNUD-FAO CHI/83/006 "Disminución de pérdidas de granos básicos postcosecha".

Luego de su realización, el Comité Organizador del evento procedió a la evaluación de las diferentes ponencias sobre los temas propuestos, formulando conclusiones y recomendaciones, algunas de las cuales se citan a continuación:

Se concluyó que:

- en Chile se han diagnosticado micotoxicosis en aves, cerdos, vacunos y peces, basándose en evidencias clínicas y patológicas. Con excepción de aflatoxinas, cuya presencia en el alimento causal ha podido demostrarse al menos en forma cualitativa en diversas ocasiones, no se han investigado otras micotoxinas en el alimento al no haberse implementado las técnicas respectivas para su identificación.

- las aflatoxinas constituyen las micotoxinas más estudiadas en Chile, aunque nunca se las ha investigado en muestras de origen animal para propósitos de diagnóstico. Por otra parte, se las ha analizado cuantitativamente preferentemente en productos importados. Las evidencias disponibles sugieren que otras micotoxinas pueden tener tanto o mayor importancia que las aflatoxinas para la industria pecuaria nacional, destacando aquellas producidas por hongos del género Fusarium

- los principales problemas en aves y cerdos han sido provocados por el consumo de alimentos elaborados con maíz nacional, habiendo aumentado su frecuencia y gravedad durante el presente año (1986). Sin embargo, al no haberse implementado técnicas oportunamente para el análisis de micotoxinas aparte de aflatoxicosis - en el país, y al no haberse generalizado el análisis cuantitativo de éstas, no pueden señalarse aún las micotoxinas prevalentes en este producto ni el nivel de su contaminación.

- la infraestructura disponible para el análisis de micotoxinas, con fines de investigación y/o servicio, es muy limitada y no permite procesar el número de muestras que demanda la problemática actual, situación que se agrava al considerar el previsible incremento en la demanda por tal servicio en el futuro próximo.

- no se pudo evaluar en su totalidad el problema de micotoxinas y micotoxicosis por la carencia de información adecuada respecto a los tipos, niveles, frecuencia y efecto de ellas en el país. Por consiguiente, tampoco pudo evaluarse el daño económico que producen las micotoxinas al sector agropecuario nacional, aunque los antecedentes disponibles lo estiman considerable.

Entre las recomendaciones se pueden citar:

- el implementar un sistema nacional de evaluación micotoxicológica, que genere y haga disponible información básica confiable sobre incidencia de hongos toxígenos en productos agropecuarios, tipos y niveles de micotoxinas en éstos y micotoxicosis en los animales de importancia económica. 
- el fortalecer la infraestructura nacional para el análisis de micotoxinas en los principales productos agrícolas, con especial énfasis en las micotoxinas de Fusarium.

- el definir con precisión dónde y cuando se producen las invasiones de hongos toxígenos y la producción de sus micotoxinas en el maíz nacional, dada la importancia de este producto para la alimentación animal.

- el investigar y transferir al nivel requerido la tecnología apropiada para prevenir, controlar y/o manejar adecuadamente el problema de la contaminación por hongos y micotoxinas, especialmente en el maíz.
- el iniciar y/o fortalecer un centro u organismo que - dentro de sus actividades - recopile, centralice y difunda informaciones nacionales $e$ internacionales relacionadas con hongos, micotoxinas y micotoxicosis, aparte de apoyar la integración y coordinación entre investigadores, productores agrícolas, pecuarios y el sector oficial.

- el continuar realizando encuentros sobre el tema en forma periódica, para fortalecer y difundir los conocimientos que se generen y evaluar los avances de las respectivas investigaciones.

\section{REFERENCIAS}

Beuchat, L.R. (1978). "Microbial alterations of grains, legumes, and oilseeds". Food Technol. 32(5): 193-197.

Bösenberg, H. (1972). "Diagnostische Möglichkeiten zum Nachweis von Aflatoxin- Vergiftungen". Zb1. Bakt. Hyg. I. Abt. Orig. A 220:252-257.

Christopher, S.Y. Y Fulcher,R.G. (1984). Mycotoxins in grains: causes, consequences and cures". Cereal Foods World. 29 (11): 725-728.

Diener, U.L. (1981). "Unwanted biological substances in foods: Aflatoxins". Aparecido en "Impact of toxicology in food processingn (Ed. John Ayres), Avi Publishing Company, Inc. Westport, Connecticut.

Frank, H.K. (1966). "Aflatoxine in Lebensmitteln". Archiv. für Lebensmittel Hygiene. 17: 237-242.

Frank, H.K (1976). "Patulin in Lebensmitteln pflanzicher Herkunft. I. Kern Obst und daraus hergestellte Produkte". Z. Lebensm. Unters. -Forsch. 162: 149-157.

Frank, H.K, Orth, R. y Figge, A. (1977). "Patulin in Lebensmitteln pflanzicher Herkunft. 2. Verschiedenen Obstarten, Gemüsse und daraus hergestellte Produkte". Z. Lebensm. Unter. -Forsch. 163:111-114.

Frank, H.K. (1979). "Toxinogene Lagerpilze bei Obst, Gemüsse und Kartoffeln". Gesunde Pflanzen 31. 68:70-72.

Frank, H.K (1980a). "Stand unserer Kenntnisse über Mykotoxine in pflanzicher Produkten". Aparecido en "XVI Vortragstagung: Qualitäts beinfluessende Faktoren pllanzicher Nahrungsmittel - Mykotoxine, Phytoalexine, Repellentien ${ }^{n}$. 5-16.

Frank, H.K (1980b). "Patulin in Produkten pflanzicher Herkunft". Confructa $25(3-4): 107-118$.

Frank, H.K. (1980c). "Mykotoxinbildende Schimmelpilze als Verderber von Früchten". Erwabsobstbau 22 (9): 196199.

Frank, H.K. (1981a). "Vorkommen von Mykotoxinen (Ausser Aflatoxine) in Getreideprodukten". Aparecido en DFGForschungsbericht "Ruickstände in Getreide und Getreideprodukten . Deutsche Forschungsgemeinschaft, Bonn.

Frank, H.K. (1981b). "Schimmelpilze und Mykotoxine in Nüssen und daraus hergestellten Produkten". Aparecido en "Mykokotoxine in Lebensmitteln". (Ed. Jurgen Reiss). Gustav Fische Verlag, Stuttgart.

Frank, H.K. (1981c). "Schimmelige Lebensmittel: Wieweit sind die Gesundheits-Schädlich?". Pharmazeutische Verfahrenstechnik Heute. Band 1: 49-53.

Frank, H.K. (1981d). "Schimmelpilze und Mykotoxine in anderer Lebens - und Genussmitteln". Aparecido en "Mykotoxine in Lebensmitteln". (Ed. Jurgen Reiss). Gustav Fischer Verlag., Stuttgart.

Graham, H.D. (1980). "The Safety of Foods". 2nd. Ed. Avi Publishing Company, Inc. Westport, Connecticut.

ICMSF (1980). "Microbial Ecology of Foods. Vol. II. Food Commodities". Academic Press, New York.

Leitsner, L. y Eckardt, C. (1981). "Schimmelpilze und Mykotoxine in Fleischerzeugnissen". Aparecido en "Mykotoxine in Lebensmitteln". (Ed. Jurgen Reiss) Gustav Fisher Verlag, Stuttgart.

López, L. (1985). "Micotoxinas y Micotoxicosis. I. Aflatoxinas". Alimentos 10 (3): $31-40$.
Majerus, P.; Woller, R; Leevivat, P. y Klintrimas, T. (1985). "Gewürze. Schimmelpilzbefall und Gehalt an Aflatoxinen, Ochratoxin A und Sterigmatocystin". Fleischwirtschaft 65 (9): $1-4$.

Marth, E.H. y Doyle, M.P. (1979). "Update on molds: Degradation of Aflatoxin". Food Technol. 33 (1): 81-87.

Mintzlaff, H.J.; Lotzsch, R. y Leistner, L. (1974). "Ubergang von. Aflatoxinen in Fleisch und Eier". Aparecido en "Unerwünschte Stoffe in Futtermitteln und mögliche Rückstande in Lebensmitteln". Fachverband der Futtermittelindustrie e.V. Hamburg.

Müller, E. y Loeffler, W. (1982). "Mykologie. Grundniss für Naturwissenschaftler und Mediziner". 4. Auflage. Georg Thieme Verlag, Stuttgart.

Palyusik, M. (1981). "Schädigungen von Wirbeltieren durch Mykotoxine". Aparecido en "Mykotoxine in Lebensmitteln". (Ed. Jurgen Reiss). Gustav Fischer Verlag, Stuttgart.

Parada, $\dot{R}$. (1986). "Micotoxicosis en bovinos". Aparecido en Tomo I. Conferencias. Encuentro Nacional sobre Micotoxinas y Micotoxicosis en el Sector Agropecuario. Estación Experimental La Platina, INIA. Santiago.

Reiss, J. (1972). "Nachweiss von Patulin in spontan verschimmelten Brot und Gebäck (Mykotoxine in Nahrungsmitteln II. Naturwissenschaften 59:37.

Reiss, J. (1981a). "Schimmelpilze und Mykotoxine in Mahlprodukten und Backwaren". Aparecido en "Mykotoxine in Lebensmitteln". (Ed. Jurgen Reiss) Gustav Fischer Verlag, Stuttgart.

Reiss, J. (1981b). "Schädigungen beim Menschen durch Mykotoxine". Aparecido en "Mykotoxine in Lebensmitteln". (Ed. Jurgen Reiss). Gustav Fischer Verlag, Stuttgart.

Riemann, H. y Bryan? F.L. (1979). "Food Borne Infections and Intoxications". 2nd. Ed. Academic Press, New York.

Senser, F. (1979). "Untersuchungen zum Aflatoxingehalt in Hasseinutssen". Gordian 5:117-123.

Siegfried, R (1977). "Fusarium Toxine". Naturwissenschaften 64: 274 .

Singh, R y Hsieh, D.P.H. (1976). "Enzymatic conversion of sterigmatocystin into aflatoxin B1 by cellfree extracs of Aspergillus parasiticus" ${ }^{\mathrm{n}}$. Appl. Environ, Microbiol. 31: 743.

Spicher, G. (1981). "Schimmelpilze und Mykotoxine in Getreide". Aparecido en "Mykotoxine in Lebensmitteln". (Ed. Jurgen Reiss) Gustav Fischer Verlag, Stuttgart.

van Walbeck, W.P.; Scott, P.M. Y Thatcher, F.S. (1968). "Mycotoxine from foodborne fungi". Can. J. Microbiol. 14: $131-137$.

Wogan, G.N. (1969). "Metabolism and biochemical effects of aflatoxins". Aparecido en "Aflatoxin, scientific backgrounds, control and implications". (Ed. L.A. Goldblath) Academic Press, New York.

Woller, R y Majerus, P. (1981). "Zur Aflatoxin-Situation in verschiedenen Lebnensmitteln". Mitt. Gebiete Lebensm. Hyg. $72: 437-440$.

Woller, R. y Majerus, P. (1981). "Zur Mykotoxin- und insbesonderes zur Aflatoxinsituation bei Bier, Ausgangsstoffen und Nebenprodukten der Bierbereitung". Brauwissenschaft 4: 88-90. 